Indexed by

\section{Scopus}

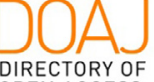

DIRECTORY OF OPEN ACCESS

Crossref

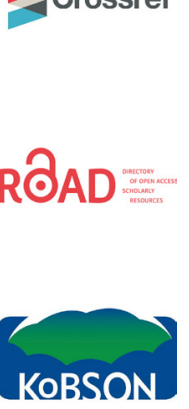

SCINDEKS

gingoogle

\title{
OPTIMIZING THE VELOCITY OF RING SHAPE PARAMETER FOR DESIGNING THE NOZZLES USING CFD
}

\section{Obai Younis}

Prince Sattam Bin Abdulaziz University, College of Engineering at Wadi Addwaser, Department of Mechanical Engineering, Wadi Addwaser, Saudi Arabia University of Khartoum, Faculty of Engineering, Department of Mechanical Engineering, Khartoum, Sudan

\section{Reem Ahmed}

Elgerafsharg Technical College, Department of Mechanical Engineering, Sudan

\author{
Ali Mohammed Hamdan \\ University of Bahri, Depart- \\ ment of Mechanical Engineer- \\ ing, Alkadroo, Sudan
}

\section{Dania Ahmed}

University of Khartoum, Faculty of Engineering, Department of Mechanical Engineering, Khartoum, Sudan

Key words: CFD, nozzles, optimization, ring shape parameter, velocity doi:10.5937/jaes0-29422

Cite article:

Younis, O., Ahmed, R., Hamdan, A.M., Ahmed, D. (2021) OPTIMIZING THE VELOCITY OF RING SHAPE PARAMETER FOR DESIGNING THE NOZZLES USING CFD, Journal of Applied Engineering Science, 19(3), 618-627, DOI:10.5937/jaes0-29422

Online aceess of full paper is available at: www.engineeringscience.rs/browse-issues 


\title{
OPTIMIZING THE VELOCITY OF RING SHAPE PARAMETER FOR DESIGNING THE NOZZLES USING CFD
}

\author{
Obai Younis ${ }^{1,2}$ *, Reem Ahmed ${ }^{3}$, Ali Mohammed Hamdan', Dania Ahmed ${ }^{2}$ \\ ${ }^{1}$ Prince Sattam Bin Abdulaziz University, College of Engineering at Wadi Addwaser, \\ Department of Mechanical Engineering, Wadi Addwaser, Saudi Arabia \\ ${ }^{2}$ University of Khartoum, Faculty of Engineering, Department of Mechanical Engineering, Khartoum, Sudan \\ ${ }^{3}$ Elgerafsharg Technical College, Department of Mechanical Engineering, Sudan \\ ${ }^{4}$ University of Bahri, Department of Mechanical Engineering, Alkadroo, Sudan
}

This study aims to optimize the velocity of ring shape parameter for designing the nozzles using computational fluid dynamics (CFD) and investigated the flow in nozzles using ANSYS, Inc. simulation software. The model geometries were defined using ANSYS FLUENT-Design Modeler platform. All nozzles were designed on unstructured triangular elements comprising of 1200000 mesh nodes. The differential governing equations were applied in ANSYS FLUENT based on a finite volume method. The distance and dimensions of ring location significantly influence the velocity of water during flow where the maximum velocity at double rings reduces the surface area at distance of $7 \mathrm{~mm}$ and $15 \mathrm{~mm}$ and $2 \times 2 \mathrm{~mm}$ dimensions. Considering 8,10 , and 12 bar liner proportions, there was an increase in the velocity at maximum points in ring shapes.

Key words: CFD, nozzles, optimization, ring shape parameter, velocity

\section{INTRODUCTION}

The fluid dynamics problems are typically complicated for solving as the system of equations is strongly nonlinear system in order to govern the phenomenon. It becomes complicated for finding accurate solutions. On the contrary, computational fluid dynamics (CFD) technology was successful in order to calculate the fluid dynamics because of the close proximity between numerical simulation, experimentation, and theory in fluid dynamics. It has been observed from the theory proposed by Back, Massier\&Gier [1] that experience is mandatory for testing the hypotheses, whereas this theory becomes important for explaining the findings. Therefore, it is essential for validating the experimental results as numerical simulation is independent of experience.

The effect of nozzle geometry and shape on flow is interacted with numerous nozzle simulations with different types of nozzles and fluids. Fluids in nozzles were examined in previous studies. For instance, the performance of fluid dynamic was studied by Brusiani, Falfari\&Pelloni [2] for three different injector hole shapes diesel nozzle cylindrical, $\mathrm{k}$ hole, and KS hole by investigating the nozzle layouts through 3D-CFD fully transient multiphase approach. The flow field was studied numerically by Tamaki et al [3] for radial turbine using CFD and variable area nozzle. The study has revealed, by examining two throat areas, that the influence was very weak with the largest opening on leakage flow on the flow field nozzle downstream. Similarly, the impact of entertainment near the nozzle inflow was examined by Babu and Mahesh [4] on spatially evolving turbulent jets and round laminar jets through direct numerical simulation (DNS). The study has revealed that the significance of nozzle inflow facilitates in setting the flow of turbulent jet simulation.

The effect of nozzles geometry was numerically examined by Matsuo et al [5] with the interaction between flow characteristics and nozzle geometry in spiral nozzle via unified platform for Spalart-Allmaras as turbulence model and aerospace computational simulation. Furthermore, Theerayut and Nuntadusit [6] have examined the flow attributes of jet from expansion pipe nozzle through the numerical simulation model and 3-D numerical simulation with standard $\mathrm{k}-\varepsilon$ turbulent model. The study has revealed that a reverse flow of ambient fluid was generated through these characteristics into the pipe nozzle chamber with the collar. Alam et al [7] have examined the impact of flow parameters at the exit of nozzles for focusing on the impact of nozzle flow parameters. The study has found that the nozzle geometry had an apparent impact on discharge coefficient via Reynolds-averaged Navier-Stokes (RANS) equations.

Belega and Nguyen [8] have examined the nozzle flow by using the convergent-divagated model and identified the fluid behaviour using CFD. Similarly, the flow in convergent-divagated nozzle was examined by Rao et al [9] with different Mach number and nozzle ratio using CFD. In addition, CFD analysis of flow was used by Satyanarayana et al [10] for different cross-sectional shapes in convergent-divagated nozzles in order to examine the appropriate nozzles for giving high-exit velocity among different cross-sections. The study has revealed that the shape of nozzle is dependent on the fluid characteristics for affecting the flow throughout the nozzle and flow expansion level. Moreover, the compressible flow in convergent-divergent nozzle was numerically simulated by Mohamed et al [11] for studying the pressure effect on the flow attributes. The turbulence was modelled by us- 
ing Reynolds averaged Naveir-Stocks (RANS) equations and two transport equations.

There is a paucity of literature discussing the numerical simulation of flow in nozzles. For instance, the effect of diesel nozzle geometry on the introduction and development of cavitation was numerically examined by Payri et al. [12] and Macian et al. [13]. Du, Liu and Tang [14] have conducted CFD for studying the nozzle internal flow and diesel fuel spray, while Masuda et al. [15] included the mixture formation in the chamber through CFD simulations. A CFD cavitation model was developed by Giannadakis, Gavaises and Arcoumanis [16] for diesel injector nozzles on the basis of Eulerian-Lagrangian approach. Giannadakis and colleagues have explained that their model can express several cavitation structures in internal nozzle flows and revealed that these structures are relied on flow conditions and nozzle design. Shan, Zhang and Huang [17], in a recent numerical and experimental study, have compared the aerodynamic performance of several micro lobed nozzle ejectors with different geometries. Shan, Zhang and Huang [17] have used the k- $\varepsilon$ standard turbulence model for conducting RANS simulations.

The majority of nozzle simulations are concerned with the impact of nozzle shape on the association of the spray or jet with the fluid downstream of the nozzle. For instance, direct numerical simulation was undertaken by Boersma, Brethouwer and Nieuwstadt [18] at a low Reynolds number of 2400 using a spatially developing free round. Boersma, Brethouwer and Nieuwstadt [18] have compared their outcomes with the simulations conducted by Hussein, Capp and George [19] and Panchapakesan and Lumley [20] and revealed better accord with the numerical simulations. The impact of inflow conditions was examined by Babu and Mahesh [4] on the inclusion of the ambient fluid into the jet exiting the nozzle.

Various scholars have assessed the accuracy of the turbulence model in order to expect the flow field and the nozzle performance by conducting the numerical and experimental studies. These studies have conducted two-dimensional axisymmetric compressible flow analysis using a CD nozzle with the assistance of ANSYS FLUENT via K- $\varepsilon$ turbulence model. In this regard, Najar, Dandotiya and Najar [21] have conducted a comparative assessment between the models on the velocity, temperature contours, vectors, and pressure for developing the efficient design conditions for CD nozzles.

There seems to be a lack of basic understanding about the changes made by the flow field with respect to the changes made in the nozzle exit region, although researchers have highlighted the significance of the initial conditions on the downstream flow at the nozzle exit plane. Thereby, it is of significant interest for developing a CFD approach for examining the turbulence and mean features of fluid flow using a nozzle, and for studying the impact of nozzle shape on the exit conditions in the post-contraction region.
CFD is a multipurpose technique of simulation and modelling of flow fields, which offers accurate findings about the flow features of an object. The complexity in the computational studies of the flow field is imposed through the solution of RANS being transient in nature, and the integration of an adequate turbulence model for closure of RANS equations. Discrepancies between the experimental measurements and numerical simulations are induced by the compressible flow regions in nozzles being dominated by complex secondary flows and intense pressure gradients.

It has been observed that different methods of analysis were covered in previous studies related to the flow of nozzles. However, numerical method has described effectively the results as compared to the experimental method, which require complicated nozzle geometries. Current modifications in building sizes and increase have raised concerns for additional water with high velocity, specifically in case of fire, for mitigating the associated obstacles. In this regard, this study has optimized the velocity of ring shape parameter in order to design the nozzles using CFD.

\section{METHODS}

The study of fluids in motion is dedicated through CFD and how processes are influenced by the fluid flow behaviour including chemical reactions and heat transfer in combusting flows. In addition, fundamental mathematical equations demonstrate the physical attributes of the fluid motion typically in the form of partial differentiation, which direct a process of interest, and are usually termed as governing equations in CFD. In this study, CFD technique has been used for examining the velocity of ring shape parameter for designing the nozzles.

Generally, the Euler-Euler and Euler-Lagrange approaches were often utilized for numerically simulating the multiphase flows. The continuous phase, in the Euler-Lagrange is modelled by explaining the time aggregated Navier-Stokes equations, whereas the disseminated phase is explained by tracking a series of droplets, bubbles, or particles via the computed continuous flow field. This approach made a fundamental postulation that the disseminated phase possesses a low-volume fraction, which would recommend that the disseminated phase attributes are not closer and must be treated as independent $[22,23]$.

On the contrary, different phases, in the Euler-Euler approach, are treated mathematically to explain ranges. However, this approach indicates that the phases separate or mix, and possesses a high-volume fraction [23, 24]. The high-volume fraction recommends that the disseminated phase attributes are closer to be considered as independent. Thereby, the engagement between the influence of the secondary phase and multiphase flow will be larger to measure for. The Volume of Fluid, Eulerian-Eulerian, and Mixture models are the three different Euler-Euler multiphase flow models. 


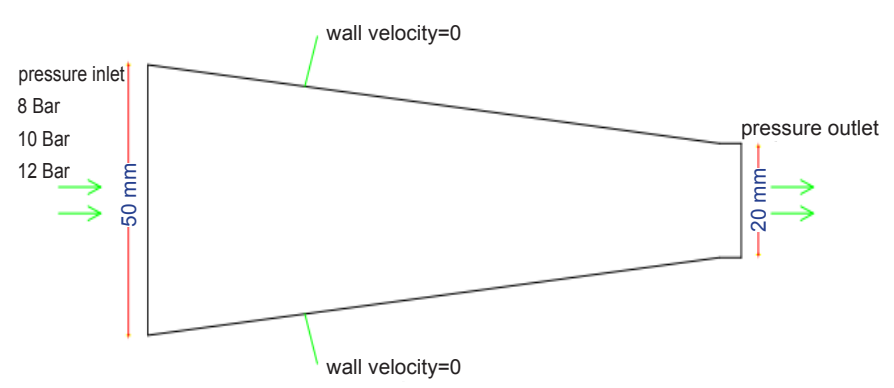

Figure 1: Geometry of the Nozzle

This study has used ANSYS, Inc. simulation software for investigating the flow in nozzles. The nozzles were defined using software: SolidWorks in order to introduce ring shapes. The dimensions proposed by Zhang et al., [25] have been used to describe the nozzle base model in this studywhich is shown in figure (1). This nozzle is $20 \mathrm{~mm}$ in diameter at the outlet, $141.96 \mathrm{~mm}$ in length, and $50 \mathrm{~mm}$ in diameter at the inlet. In addition, this study has presented all nozzles with equal length and inlet and outlet diameters for the nozzles.

The shapes of the physical boundaries of the fluid are specified through the nozzle geometries definition. ANSYS FLUENT-Design Modeler platform was used to define the model geometries. A 2D analysis type was selected for defining the nozzle dimensions based on the model. The shapes and computing areas of nozzles were drawn through ANSYS CFD software.

The total mesh number of nodes (1200000) was adopted for unstructured triangular elements on surfaces for all nozzlesas shown in figure (2). Coarse grid solutions might be affected by the mesh topology and element type topology, and in turns achieved a grid-independent solution by affecting the mesh resolution. In addition, the mesh sizes increment was progressively reduced by the number of extension nodes using an exponential growth function where the aspects were positioned away from the outlet and inlet regions. The level of grid sizes from coarse to fine were ascended by the number of elements directly proportional to the numbers of nodes. The study has selected medium mesh level with high smoothing in order to

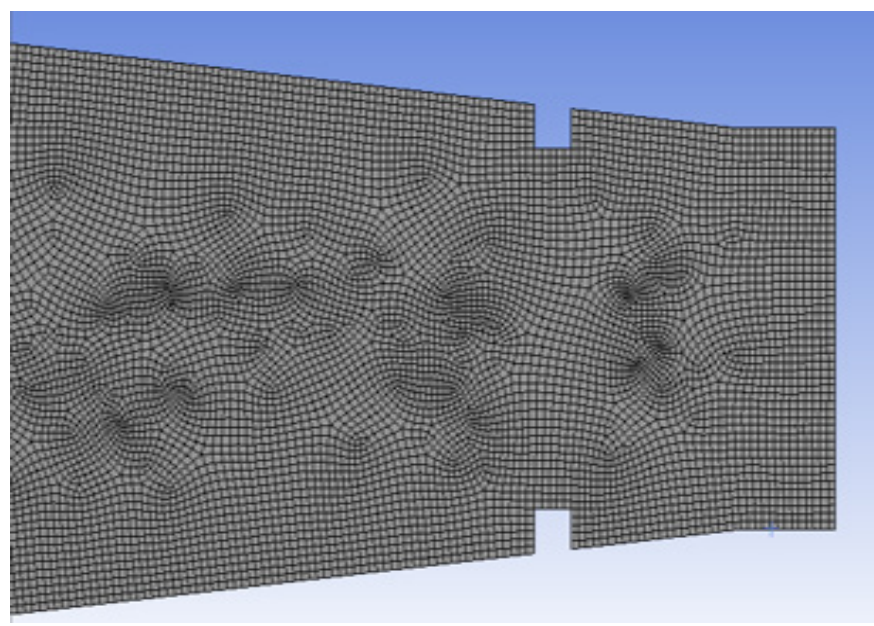

Figure 2: mesh generation

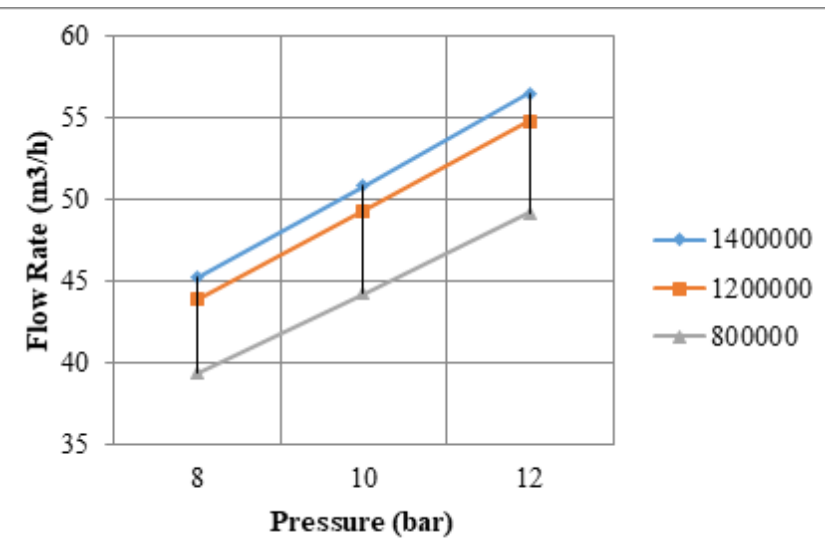

Figure 3: Flow rate for different mesh number

represent the mesh density. It is observed that the turbulence is captured through the fine mesh rather than the interior domain. The number of grids points and computational time was reduced by this possession (Table 1).

Table 1: Mesh type and number of nodes

\begin{tabular}{|c|c|c|c|}
\hline Mesh & coarse & medium & fine \\
\hline Number of nodes & 800000 & 1200000 & 1400000 \\
\hline
\end{tabular}

Figure 3 shows the volume flow rate computed at three different values of pressure ( 8,10 and 12 bar) for using the three different types of mesh mentioned in Table 1. It can be noticed that the results achieved by medium and fine mesh are almost identical. Therefore, the medium mesh is selected as a reference mesh number for all cases in this study. almost identical. Therefore, the medium mesh is selected as a reference mesh number for all cases in this study.

Validation is the preliminary mean for evaluating the accuracy and reliability in computational simulations. A well-documented benchmark experimental or numerical data has to be used to validate the process that assess modelling uncertainty. In order to validate the numerical approach utilized in this study, the obtained CFD results were compared with the numerical data of Zhang et al. [25]. Figure 4 presents the comparison between current study and Zhang et al. [25] for axial velocity component. It is clear that a very good agreement between the results of current study and of Zhang et al. [25] is obtained.

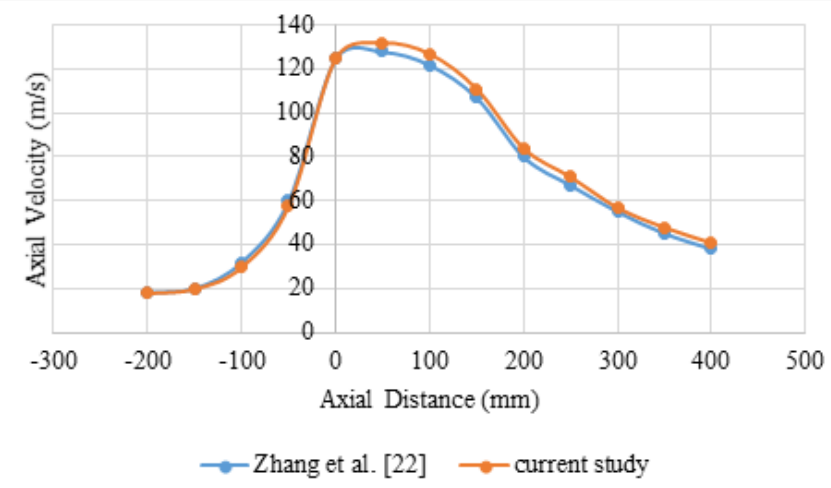

Figure 4: Axial velocity component (current study Vs. Zhang et al. [25]) 


\section{Boundary Conditions}

The inlet of nozzles was shown with a pressure of 8 bar, 10 bar, and 12 bar, respectively, and the outlet pressure of 1.10235 bar. No slip condition describes the boundary conditions at the wall including grooves, rings, and nozzle. This refers to the relative velocity between the fluid and wall, which was adjusted at zero. For all models, flow analysis was conducted in steady state mode.

\section{Solver}

ANSYS FLUENT 15.0 was selected for the simulations of the CFD technique. With the consideration given to viscous, monophasic, and incompressible fluid and isothermal process fluid motion, CFD simulations were simulated for turbulent flows in steady state. During the numerical computing, a finite volume method was applied to solve the differential governing equations in ANSYS FLUENT. The upwind scheme of second order was performed for the spatial discretization for all conservation equations and for the fluids. Similarly, the pressure and velocity were coupled in this phase using SIMPLE scheme. The second-order accuracy was selected for the overall spatial discretization. A liquid-water is selected as material for the overall spatial discretization.

Following are the parameters selected for the solution controls (Table 2):

- Turbulence Dissipation rate $=0.8$

- Turbulence Kinetic Energy $=0.8$

- A default under relaxation factor

Table 2: Analysis Procedure followed for both rings

\begin{tabular}{|l|l|}
\hline Procedure & Details \\
\hline $\begin{array}{l}\text { Problem set up } \\
\text { General- solver }\end{array}$ & $\begin{array}{l}\text { Type: pressure-based Veloci- } \\
\text { ty: absolute } \\
\text { Time: steady } \\
\text { 2D space: planar }\end{array}$ \\
\hline Models & $\begin{array}{l}\text { Viscous: turbulent } \\
\text { SST k- } \omega\end{array}$ \\
\hline Materials & liquid, water \\
\hline Boundary condition & $\begin{array}{l}\text { Inlet: pressure inlet } \\
\text { At 8,10 \&12 bar } \\
\text { Outlet: pressure outlet }\end{array}$ \\
\hline Reference value & $\begin{array}{l}\text { Compute from: inlet } \\
\text { Reference zone: solid surface } \\
\text { body }\end{array}$ \\
\hline initialization & Hybrid initialization \\
\hline
\end{tabular}

Through these properties, residual monitoring was ensured whereas convergence criteria were prepared. The iterations continue after adjusting the number of iterations to capture the convergence. The configuration and dimensions of all studied cases are summarized in Table 3.
Table 3: Nozzle Model Types and Associated Parameters

\begin{tabular}{|l|l|}
\hline $\begin{array}{l}\text { Nozzle Model } \\
\text { type (Rings) }\end{array}$ & Geometries parameters \\
\hline Model a & $\begin{array}{l}\text { One ring with dimensions of } 1 \times 1 \\
\mathrm{~mm} \text { and distance from nozzle exit } \\
10 \mathrm{~mm} .\end{array}$ \\
\hline Model b & $\begin{array}{l}\text { One ring with dimensions of } 1 \times 1 \\
\mathrm{~mm} \text { and distance from nozzle exit } \\
15 \mathrm{~mm} .\end{array}$ \\
\hline Model c & $\begin{array}{l}\text { One ring with dimensions of } 2 \times 2 \\
\mathrm{~mm} \text { and distance from nozzle exit } \\
10 \mathrm{~mm} .\end{array}$ \\
\hline Model d & $\begin{array}{l}\text { One ring with dimensions of } \\
2 \times 2 \mathrm{~mm} \text { and distance from nozzle } \\
\text { exit } 15 \mathrm{~mm} .\end{array}$ \\
\hline Model e & $\begin{array}{l}\text { Double rings with dimensions of } \\
1 \times 1 \mathrm{~mm}, 7 \mathrm{~mm} \text { distance for first } \\
\text { ring and } 15 \mathrm{~mm} \text { for second ring } \\
\text { from nozzle exit. }\end{array}$ \\
\hline Model f & $\begin{array}{l}\text { Double rings with dimensions of } \\
2 \times 2 \mathrm{~mm}, 7 \mathrm{~mm} \text { distance for first } \\
\text { ring and } 15 \mathrm{~mm} \text { for second ring } \\
\text { from nozzle exit. }\end{array}$ \\
\hline
\end{tabular}

\section{RESULTS}

The velocity of water during flow was significantly affected by the distance and dimensions of ring location, specifically where the maximum velocity was given by double rings with $2 \times 2 \mathrm{~mm}$ dimensions and distance of $7 \mathrm{~mm}$ and $15 \mathrm{~mm}$ from nozzle exit in order to reduce the surface area. The optimization was found to be positive where the velocity increased with the increase in pressure. It was also established that the mean velocity was substantially increased with the presence of ring at the exit, and needs a much higher inlet pressure for moving the fluid using the nozzle. In addition, the narrowest outlet section in all nozzle types is reported through the maximum value of velocity at the outlet section.

Similarly, the distance of $7 \mathrm{~mm}$ and $15 \mathrm{~mm}$ for the first ring and second ring with $2 \times 2 \mathrm{~mm}$ dimensions were selected for changing the ring to double rings. The velocity was increased at maximum point considering at all pressure 8 , 10 , and 12 bar liner proportion. Due to the number of rings and its associated dimensions, the surface area might be affected because of this change and $2 \times 2 \mathrm{~mm}$ dimension. In addition, Table 4 presents the changes in number of rings to double rings with $7 \mathrm{~mm}$ distance for first ring and $15 \mathrm{~mm}$ distance for second ring along with $1 \times 1 \mathrm{~mm}$ dimensions. It has been observed that variations exist between the increase in velocity at 8 bar, $10 \mathrm{bar}$, and $12 \mathrm{bar}$ liner proportion, which reduced the surface area. 
Table 4: Results analysis for rings

\begin{tabular}{|l|c|c|c|}
\hline \multirow{2}{*}{ Models type (Ring) } & \multicolumn{3}{|c|}{ Velocity (m/s) } \\
\cline { 2 - 4 } & At 8 (bar) & At 10 (bar) & At 12 (bar) \\
\hline Model a & 41.8 & 46.7 & 51.1 \\
\hline Model b & 47 & 52.6 & 57.7 \\
\hline Model c & 41.1 & 46.2 & 50.9 \\
\hline Model d & 42.3 & 48.5 & 51.8 \\
\hline Model e & 45.7 & 51.1 & 56 \\
\hline Model f & 49.1 & 55.1 & 60.6 \\
\hline
\end{tabular}

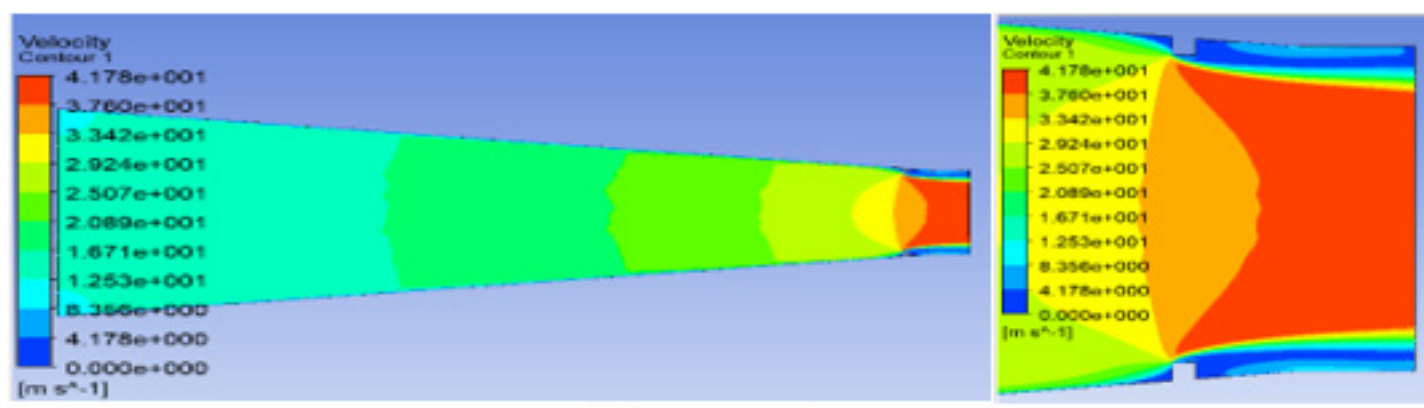

a) Pressure 8 bar

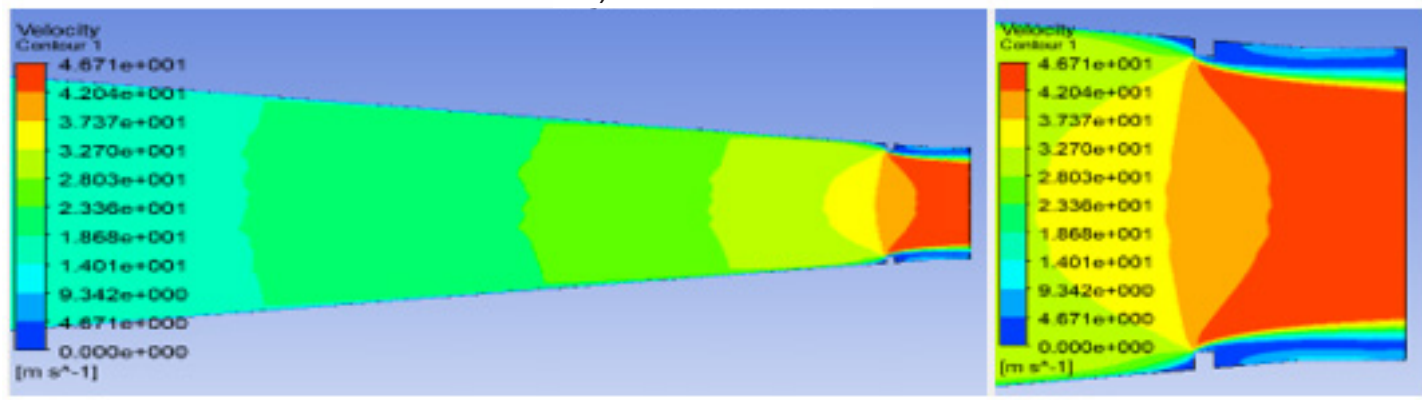

b) Pressure 10 bar
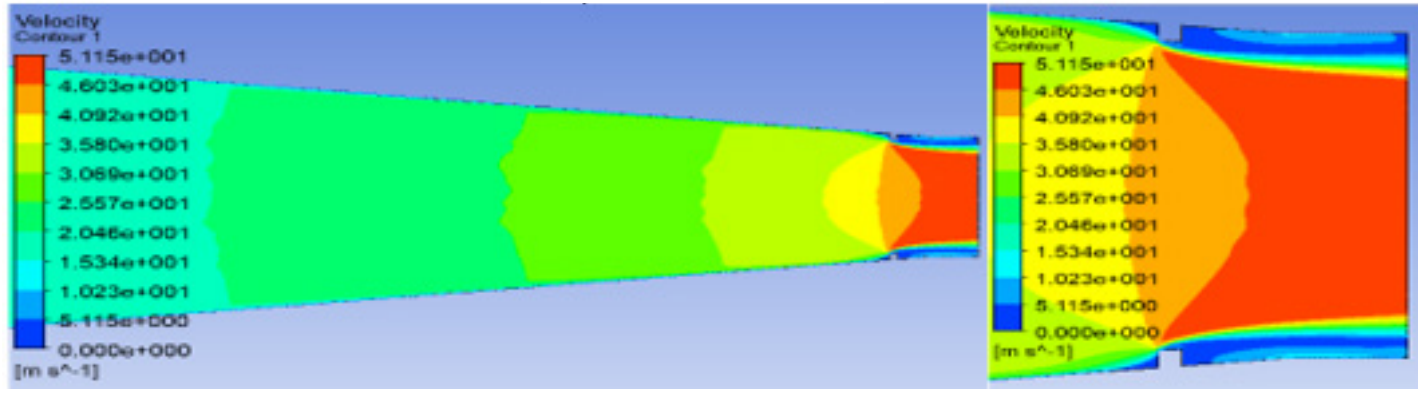

c) Pressure 12 bar

Figure 5: Velocity contours of first ring model with dimensions of $1 \times 1 \mathrm{~mm}$ and distance from nozzle exit at $10 \mathrm{~mm}$

The effect of ring dimensions $1 \times 1(\mathrm{~mm})$ located $10 \mathrm{~mm}$ at 8 bar, 10 bar, and 12 bar, in velocity of water during flow in the nozzle is shown in Figure 5. The model reveals that the relationship of pressure and effect of ring dimension $1 \times 1 \mathrm{~mm}$ and distance is proportion.
Figure 6 shows the effect of ring dimensions $2 \times 2(\mathrm{~mm})$ and location $10 \mathrm{~mm}$ at 8 bar, 10 bar and 12 bar, in velocity of water during flow in the nozzle. The model revealed that the relationship of pressure and effect of ring dimension $1 \times 1$ $\mathrm{mm}$ and distance $15 \mathrm{~mm}$ is proportion relationship, and rate of velocity is more than the model presented in Figure 5. 


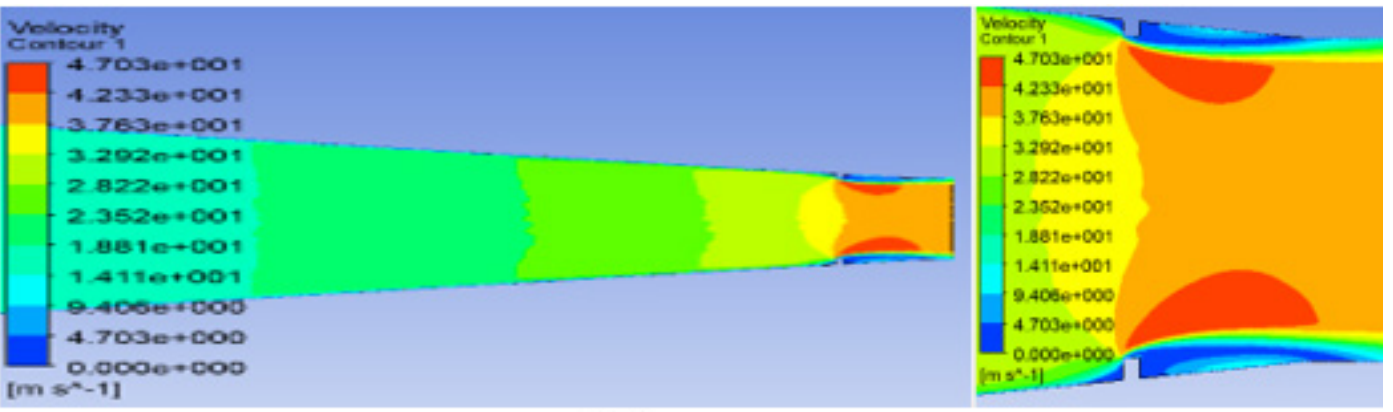

a) 8 bars
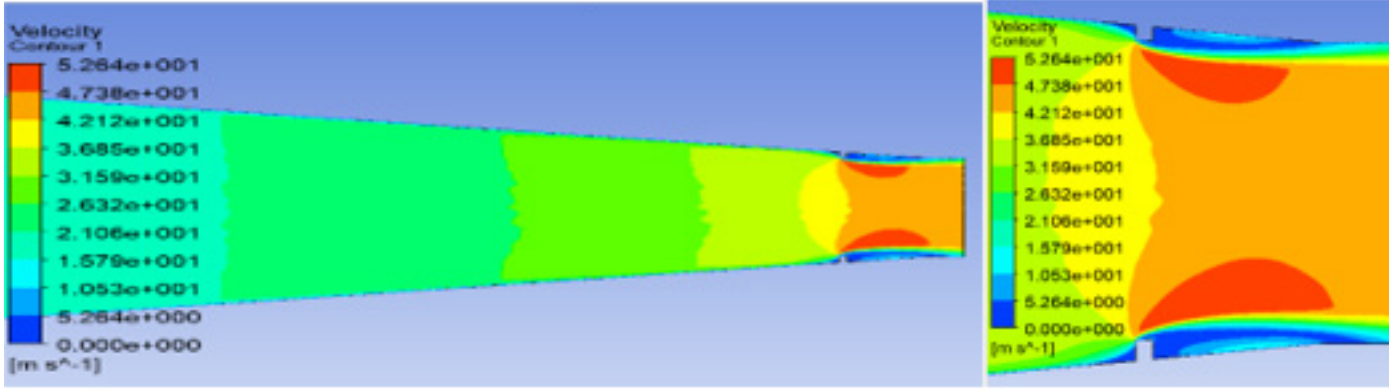

b) 10 bars

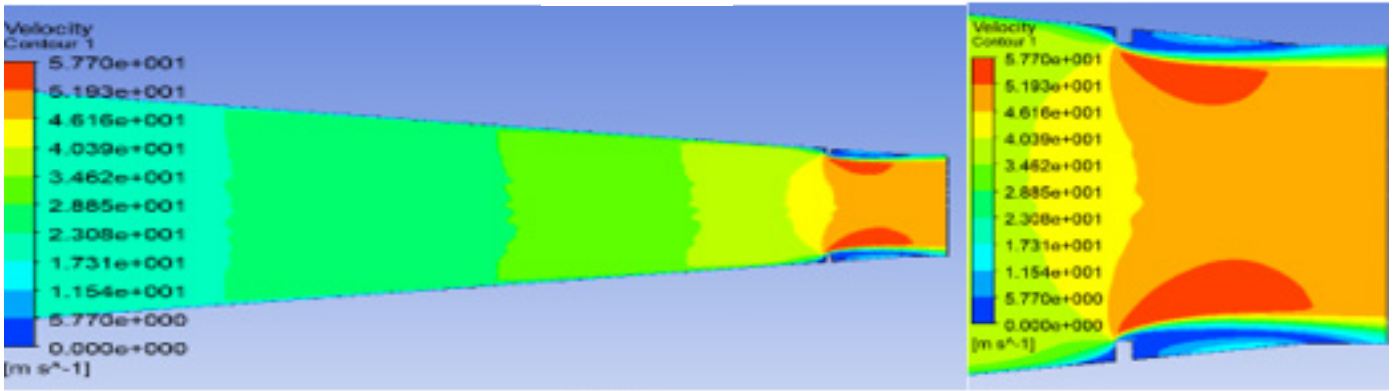

c) 12 bars

Figure 6: Velocity contours of first second ring model with dimensions of $1 \times 1 \mathrm{~mm}$ and distance from nozzle exit at $15 \mathrm{~mm}$

Figure 7 reflects the effect of the ring with $2 \times 2 \mathrm{~mm}$ dimensions and distance of ring location is $10 \mathrm{~mm}$ far away from exit of the nozzle. It also exhibits its effect in velocity increased at 8 bars, and at 10 bars; while, at 12 bar the velocity increased more than 8 bar and 10 bars. This variation shows that when ring thickness increased the velocity decreased because of water separation caused by distance reduction.

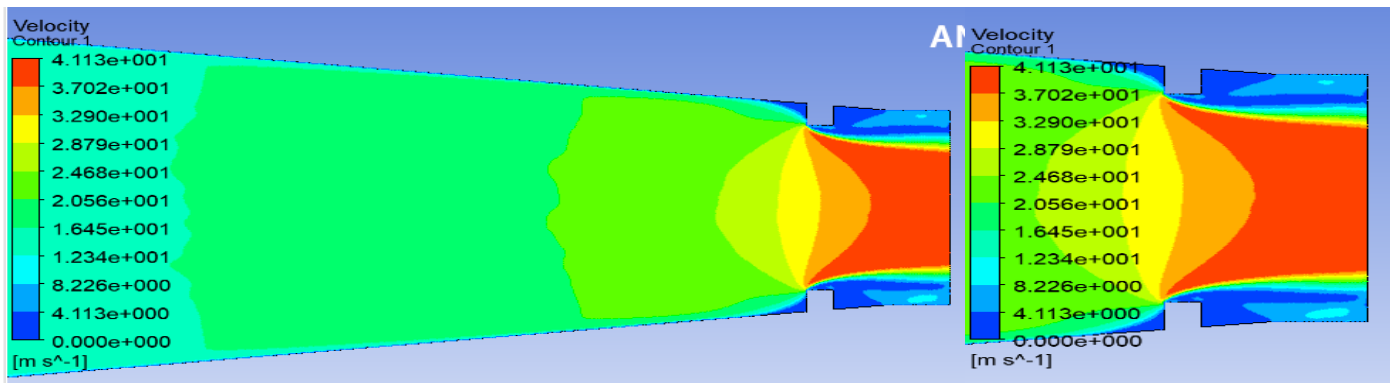

a) 8 bars

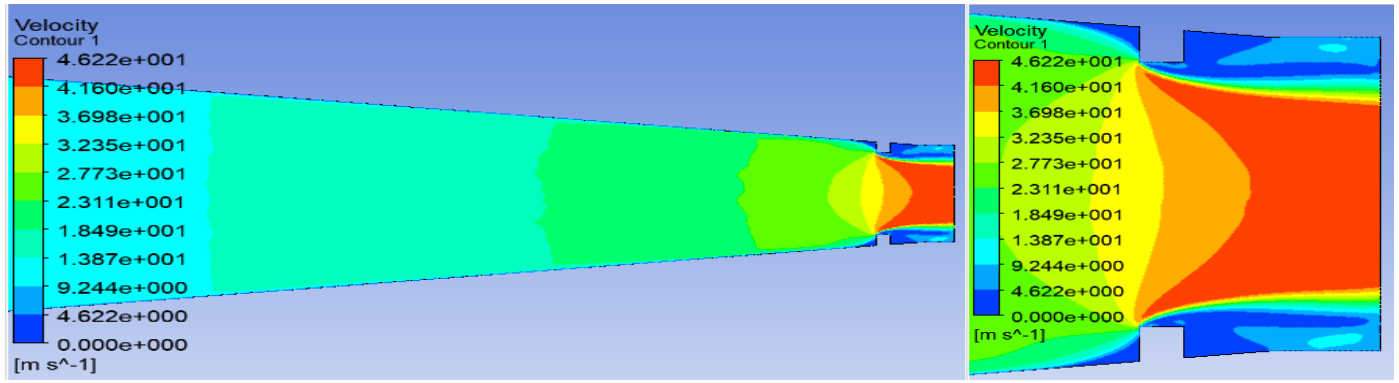

b) 10 bars 


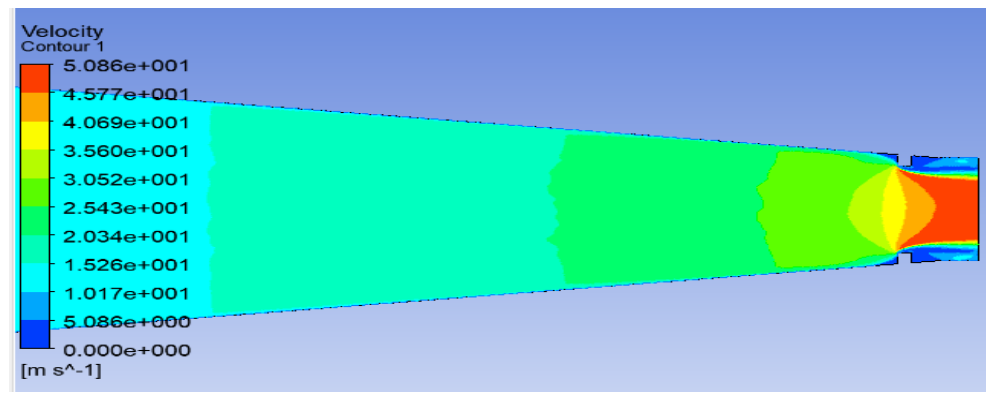

c) 12 bar

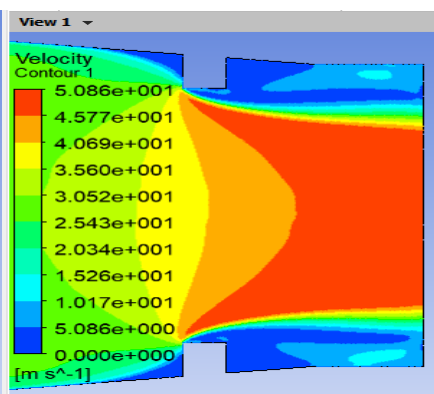

$0.0000+000$

Figure 7: Velocity contours of first third ring model with dimensions of $2 \times 2 \mathrm{~mm}$ and distance from nozzle exit at $10 \mathrm{~mm}$

Figure 8 shows the effect of ring dimensions $2 \times 2(\mathrm{~mm})$ and location $15 \mathrm{~mm}$ at 8 bar, 10 bar and 12 bars, in velocity of water during flow in the nozzle. This model reveals that the relationship of pressure and effect of ring dimension $2 \times 2 \mathrm{~mm}$ and distance $15 \mathrm{~mm}$ is proportion. This may be due to difference in ring dimensions and increase in ring thickness that decreases velocity because of water separation caused by distance reduction.

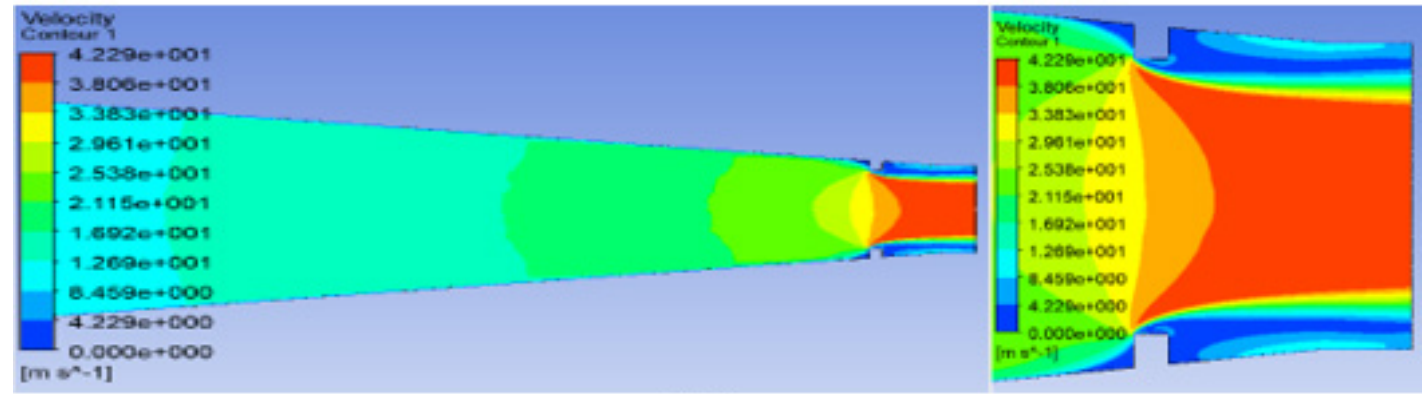

a) 8 bars

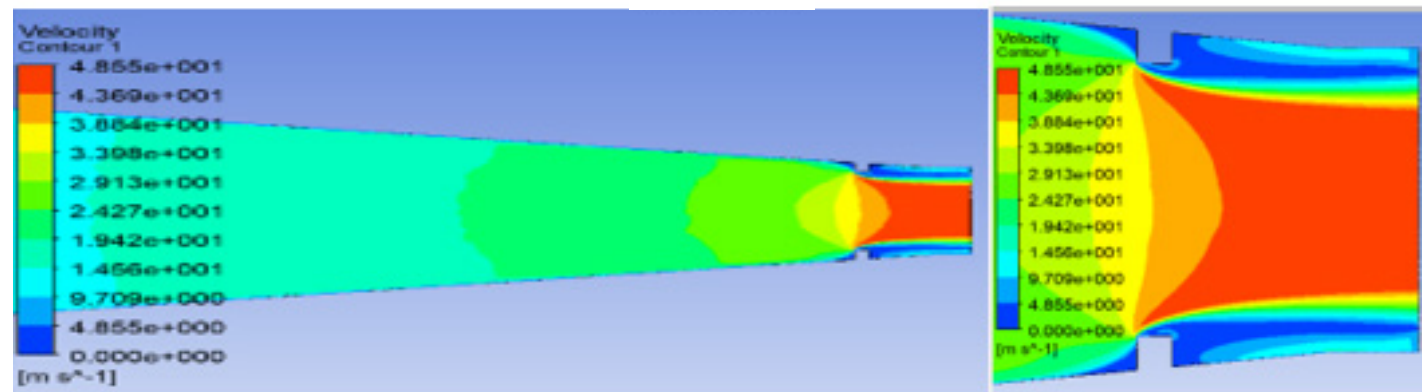

b) 10 bars

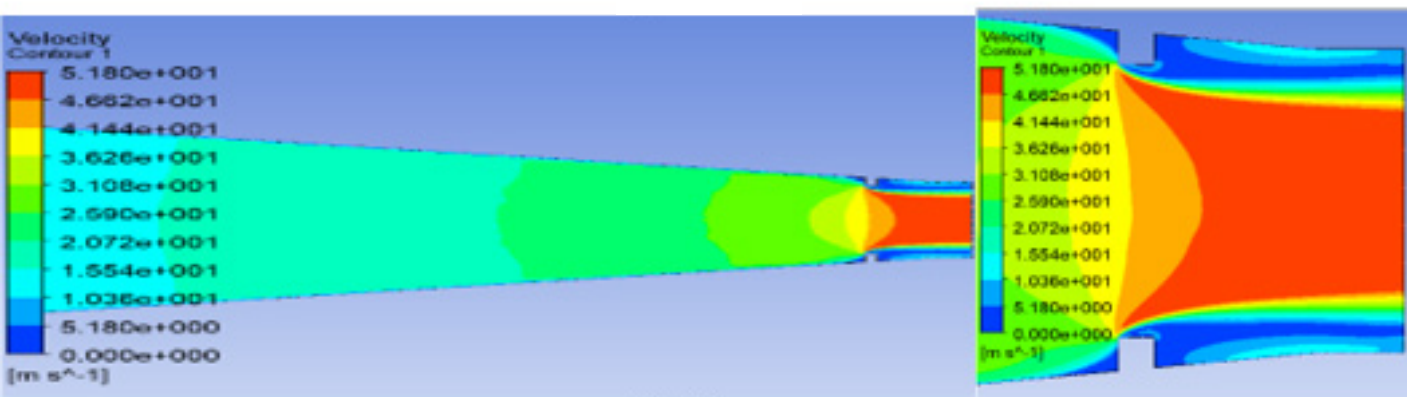

c) $\uparrow 2$ bar

Figure 8: Velocity contours of fourth ring model with dimensions of $2 \times 2 \mathrm{~mm}$ and distance from nozzle exit at $15 \mathrm{~mm}$

Figure 9 illustrates the effect of double rings dimensions $1 \times 1(\mathrm{~mm})$ and location $7 \mathrm{~mm}$ for the first and $15 \mathrm{~mm}$ for second ring from the exit at 8 bar, 10 bar and 12 bars, in velocity of water during flow in the nozzle. The results demonstrate that its effect in velocity increased at 8 bar, 10 bar and 12 bar velocity because they at $10 \mathrm{~mm}$ distances, unlike Figure 2. 


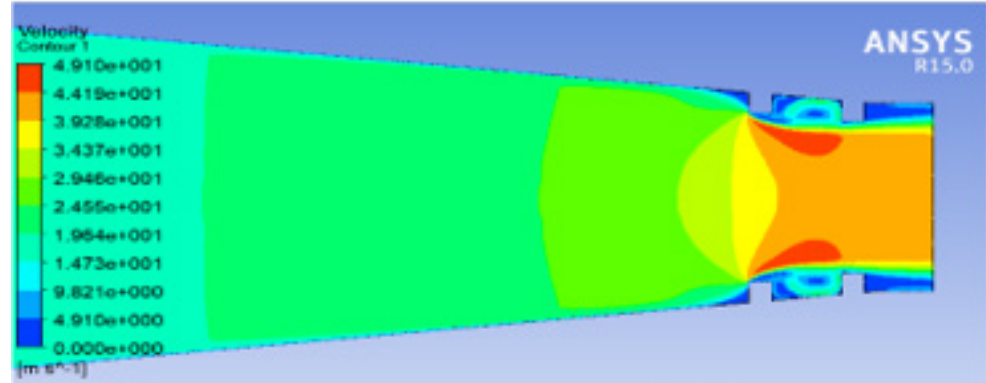

At 8 bars

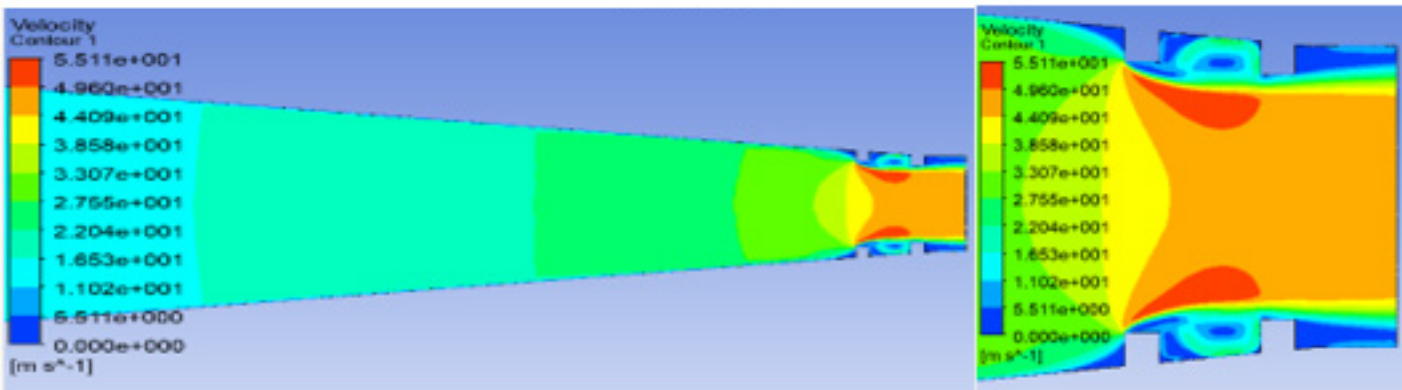

At 10 bars

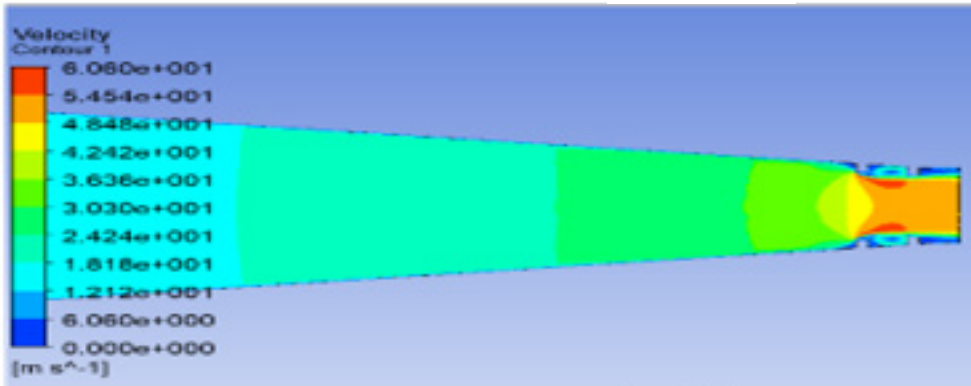

At 12 bars
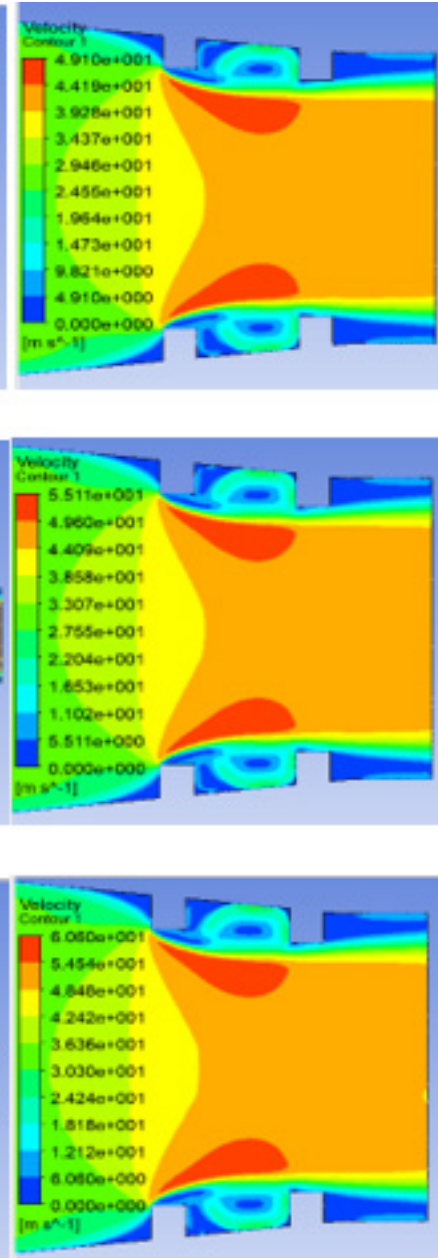

Figure 9. Velocity contours of fifth ring model with dimensions of $1 \times 1 \mathrm{~mm}, 7 \mathrm{~mm}$ distance for first ring and $15 \mathrm{~mm}$ for second ring from nozzle exit

Figure 10 shows the effect of double rings dimensions increased at 8 bar and also increased in 10 bar and 12 $2 \times 2(\mathrm{~mm})$ and location $7 \mathrm{~mm}$ for the first and $15 \mathrm{~mm}$ for second ring from the exit at 8 bar, 10 bar and 12 bars, in velocity of water during flow in the nozzle. The velocity bars in liner proportion due to number of rings and its dimension that reduced the surface area.
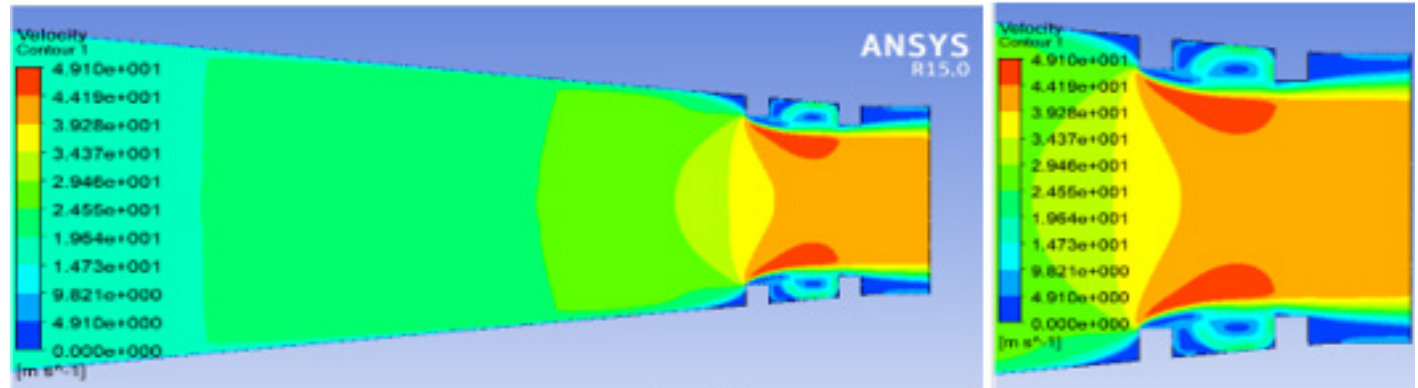

At 8 bars

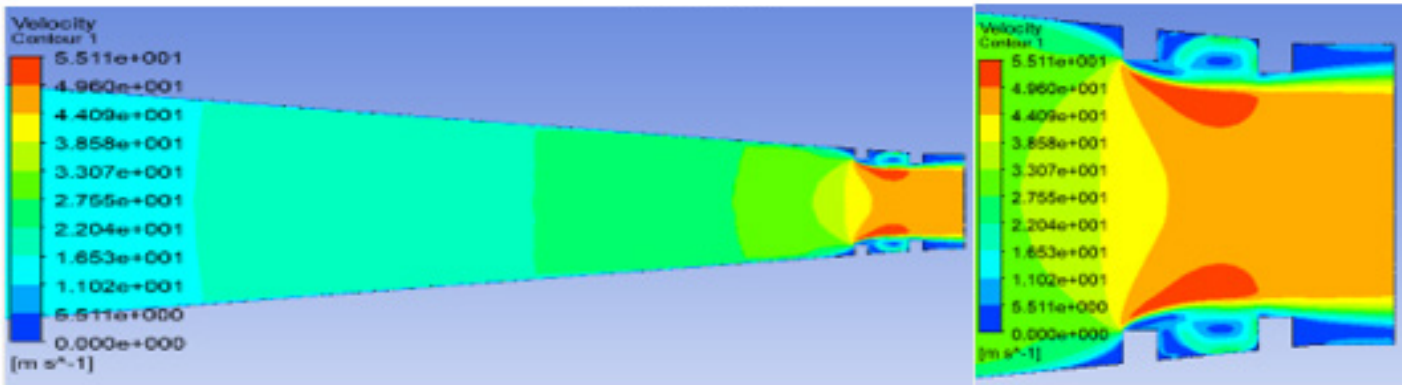

At 10 bars 


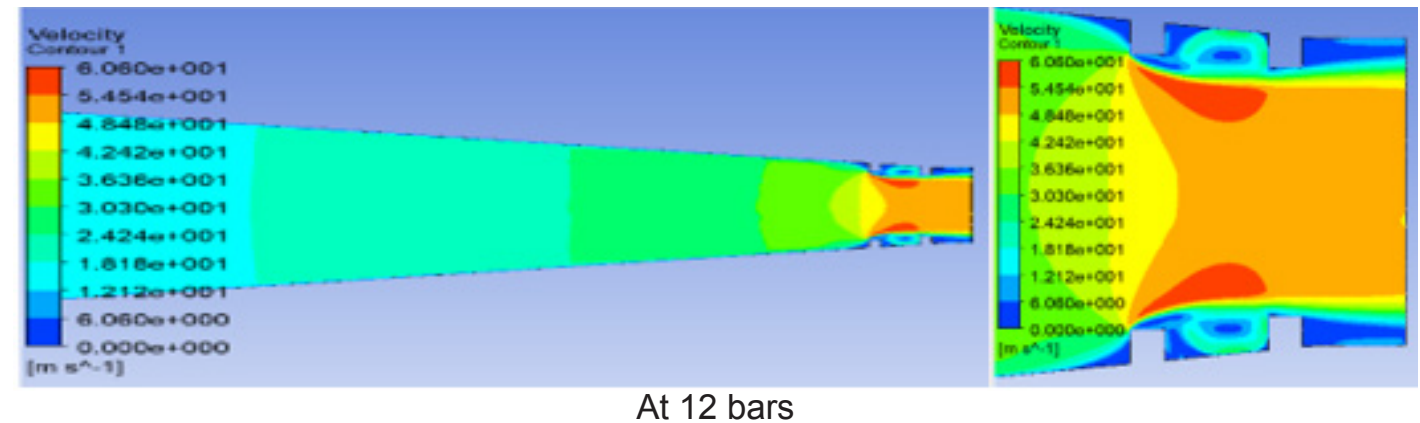

Figure 10: Velocity contours of sixth ring model with dimensions of $2 \times 2 \mathrm{~mm}, 7 \mathrm{~mm}$ distance for first ring and $15 \mathrm{~mm}$ for second ring from nozzle exit

The results have clearly shown that there is significant impact of dimensions and distance of ring location on the velocity of water during flow, especially where double rings with dimensions with $2 \times 2 \mathrm{~mm}$ and distance $7 \mathrm{~mm}$ and $15 \mathrm{~mm}$ from nozzle exit. This condition offers maximum velocity as the result of decrease in surface area. The rationale for this mechanism can be explained by the presence of large separation that reattaches near the exit of the ringed nozzle. The exit flow increases, along with re-entrant flow near walls due to elongated recirculation zone as the baseline nozzle is stimulated with an added ring.

Therefore, it is stated that velocity increases as the surface area of nozzle decreases. The result stating that there is significant positive effect of increase in pressure on velocity is in agreement with Yu et al. [26]. Moreover, the analysis also showed that presence of a ring significantly increases mean velocity at the exit and increased inlet pressure is required to move the fluid through the nozzle. These results are consistent with one of the previous studies conducted by Bilir et al. [27], who showed that narrow outlet section in all nozzle types helps velocity to reach at its maximum value.

\section{CONCLUSION}

The two-dimensional steady flows were simulated for investigating the effect of velocities in the nozzles undertaking different pressures. The study has adjusted twelve monitoring sections in the nozzles horizontally. The core objective of this study was to optimize the ring shape velocities on the water flow. The study has applied the water passing through the nozzle shapes for alleviating the velocities. A homogenous flow assumption and steady simulation was used for simulating the entire flow passage of models through shear stress transport equations along with standard turbulent model. The nozzle was compared with the simulation results regardless of any modification. Better expectations were reflected through these results regarding the use of rings in order to enhance operation of nozzles in the same dimension for increasing water velocity. It was observed that no changes were made in different parameters with the modifications made in the nozzle for grooves.

Therefore, considering the results, future studies can utilize these models for increasing the velocities and improving the surface area covered by water. Future studies should consider adopting short distance for decreasing the velocity and separating the water. Additional rings should be applied for gaining more insights on effects of velocities.

\section{ACKNOWLEDGEMENT}

This publication was supported by the Deanship of Scientific Research at Prince Sattam bin Abdulaziz University, Alkharj, Saudi Arabia.

\section{REFERENCES}

1. Back, L.H., Massier, P.F., Gier, H.L. (1964). Convective heat transfer in a convergent-divergent nozzle. International Journal of Heat and Mass Transfer, vol. 7, no. 5, 549-568. Doi: https://doi.org/10.1016/00179310(64)90052-3

2. Brusiani, F., Falfari, S., Pelloni, P. (2014). Influence of the Diesel injector hole geometry on the flow conditions emerging from the nozzle. Energy Procedia, vol. 45, 749-758. Doi: https://doi.org/10.1016/j.egypro.2014.01.080

3. Tamaki, H., Unno, M., Iwakami, A. Ishii, S., (2007). Study on flow fields in variable area nozzles for radial turbines. IHI Engineering review, vol. 40, no. 2, 89-97. nc. Doi: https://doi.org/10.5293/ijfms.2008.1.1.047

4. Babu, P.C. Mahesh, K. (2004). Upstream entrainment in numerical simulations of spatially evolving round jets. Physics of Fluids, vol. 16, no. 10, 36993705. Doi: https://doi.org/10.1063/1.1780548

5. Matsuo, S., Kim, T.H., Setoguchi, T., Kim, H.D. Lee, Y.W. (2007). Effect of nozzle geometry on the flow characteristics of spiral flow generated through an annular slit. Journal of Thermal Science, vol. 16, no. 2, 149-154. Doi: https://doi.org/10.1007/s11630-0070149-4

6. Theerayut, K.S.M.W.H. Nuntadusit, L.C. (2012). Effect of nozzle geometry on flow characteristic of jet from expansion pipe nozzle. 
7. Alam, M.M.A., Setoguchi, T., Matsuo, S., Kim, H.D. (2016). Nozzle geometry variations on the discharge coefficient. Propulsion and Power Research, vol. 5, no. 1, 22-33. Doi: https://doi.org/10.1016/j. jppr.2016.01.002

8. Belega, B.A. Nguyen, T.D. (2015). Analysis of flow in convergent-divergent rocket engine nozzle using computational fluid dynamics. In Proceedings of International Conference of Scientific Paper AFASES. Brasov, Romania.

9. Rao, G.R., Ramakanth, U.S. Lakshman, A. (2013). Flow analysis in a convergent-divergent nozzle using CFD. International Journal of Research in Mechanical Engineering, vol. 1, no. 2, 136-144.

10. Satyanarayana, G., Varun, C. Naidu, S.S., (2013). CFD analysis of convergent-divergent nozzle. Acta Technical Corviniensis-Bulletin of Engineering, vol. 6, no. 3, 139.

11. Mohamed, S., Mokhtar, A. Chatti, T.B. (2017). Numerical simulation of the compressible flow in convergent-divergent nozzle. International Journal of Heat and Technology, vol. 35, no. 1, 673-677. Doi: https://doi.org/10.18280/ijht.350328

12. Payri, R., García, J.M., Salvador, F.J. Gimeno, J., (2005). Using spray momentum flux measurements to understand the influence of diesel nozzle geometry on spray characteristics. Fuel, vol. 84, no. 5, 551561. Doi: https://doi.org/10.1016/j.fuel.2004.10.009

13. Macián, V., Payri, R., Margot, X. Salvador, F.J. (2003). A CFD analysis of the influence of diesel nozzle geometry on the inception of cavitation. Atomization and sprays, vol. 13, no. 5\&6. Doi: https:// doi.org/10.1615/atomizspr.v13.i56.80

14. Du, H., Liu, J. Tang, J. (2008). A CFD Investigation on the Nozzle of Orifices Distributing in Different Space Layers (No. 2008-01-0948). SAE Technical Paper. Doi: https://doi.org/10.4271/2008-01-0948

15. Masuda, R., Fuyuto, T., Nagaoka, M., von Berg, E. Tatschl, R. (2005). Validation of diesel fuel spray and mixture formation from nozzle internal flow calculation (No. 2005-01-2098). SAE Technical Paper. Doi: https://doi.org/10.4271/2005-01-2098

16. Giannadakis, E., Gavaises, M. Arcoumanis, C. (2008). Modelling of cavitation in diesel injector nozzles. Journal of Fluid Mechanics, vol. 616, 153-193. Doi: https://doi.org/10.1017/s0022112008003777

17. Shan, Y., Zhang, J.Z. Huang, G.P. (2011). Experimental and numerical studies on lobed ejector exhaust system for micro turbojet engine. Engineering Applications of Computational Fluid Mechanics, vol. 5, no. 1, 141-148. Doi: https://doi.org/10.1080/19942 060.2011 .11015358
18. Boersma, B.J., Brethouwer, G. Nieuwstadt, F.T. (1998). A numerical investigation on the effect of the inflow conditions on the self-similar region of a round jet. Physics of fluids, vol. 10, no. 4, 899-909. Doi: https://doi.org/10.1063/1.869626

19. Hussein, H.J., Capp, S.P. George, W.K. (1994). Velocity measurements in a high-Reynolds-number, momentum-conserving, axisymmetric, turbulent jet. Journal of Fluid Mechanics, vol. 258, 31-75. Doi: https://doi.org/10.1017/s002211209400323x

20. Panchapakesan, N.R. Lumley, J.L. (1993). Turbulence measurements in axisymmetric jets of air and helium. Part 1. Air jet. Journal of Fluid Mechanics, vol. 246, 197-223. Doi: https://doi.org/10.1017/ s0022112093000096

21. Najar, N.A., Dandotiya, D. Najar, F.A. (2013). Comparative analysis of $k-\varepsilon$ and spalart-allmaras turbulence models for compressible flow through a convergent-divergent nozzle. The International Journal of Engineering and Science (IJES), vol. 2, no. 8.

22. Brennan, M.S., Narasimha, M., Holtham, P.N. (2007). Multiphase modelling of hydrocyclones-prediction of cut-size. Minerals Engineering, vol. 20, no. 4, pp.395-406. Doi: https://doi.org/10.1016/j.mineng.2006.10.010

23. Crowe, C.T., Schwarzkopf, J.D., Sommerfeld, M., Tsuji, Y. (2011). Multiphase flows with droplets and particles. CRC press.

24. Lim, E.W.C., Chen, Y.R., Wang, C.H., Wu, R.M. (2010). Experimental and computational studies of multiphase hydrodynamics in a hydrocyclone separator system. Chemical Engineering Science, vol. 65, no. 24, 6415-6424. Doi: https://doi.org/10.1016/j. ces.2010.09.029

25. Zhang, S.B. Zhu, J.M. (2013). Numerical simulation of adjustable nozzles. In IOP Conference Series: Materials Science and Engineering. vol. 52, no. 7, 072014. IOP Publish. Doi: https://doi. org/10.1088/1757-899x/52/7/072014

26. Yu, Y., Shademan, M., Barron, R.M., Balachandar, R. (2012). CFD study of effects of geometry variations on flow in a nozzle. Engineering applications of computational fluid mechanics, vol, 6 , no. 3, pp. 412-425. Doi: https://doi.org/10.1080/19942060.201 2.11015432

27. Bilir, A.Ç., Doğrul, A., Coşgun, T., Yurtseven, A., Vardar, N. (2016). A numerical Investigation of the Flow in Water Jet Nozules. Journal of Thermal Engineering, vol. 2, no. 5, 907-912. Doi: https://doi. org/10.18186/jte.55087

Paper submitted: 17.11.2020.

Paper accepted: 02.03.2021.

This is an open access article distributed under the CC BY 4.0 terms and conditions. 


\title{
OPTIMAL THERMAL SENSORS PLACEMENT BASED ON INDOOR THERMAL ENVIRONMENT CHARACTERIZATION BY USING CFD MODEL
}

\author{
Faridah $^{1,2}$, Sentagi Sesotya Utami ${ }^{1 *}$, Ressy Jaya Yanti', Sunarno ${ }^{1}$, Emilya Nurjani $^{2}$, Rony Wijaya ${ }^{1}$ \\ ${ }^{1}$ Universitas Gadjah Mada, Faculty of Engineering, Department of Nuclear Engineering and Engineering \\ Physics, Yogyakarta, Indonesia \\ ${ }^{2}$ Universitas Gadjah Mada, Graduate School, Doctorate Program in Enviromental Science, Yogyakarta, Indonesia
}

This paper discusses an analysis to obtain the optimal thermal sensor placement based on indoor thermal characteristics. The method relies on the Computational Fluid Dynamics (CFD) simulation by manipulating the outdoor climate and indoor air conditioning (AC) system. First, the alternative sensor's position is considered the optimum installation and the occupant's safety. Utilizing the Standardized Euclidean Distance (SED) analysis, these positions are then selected for the best position using the distribution of the thermal parameters' values data at the activity zones. Onsite measurement validated the CFD model results with the maximum root means square error, RMSE, between both data sets as $0.8^{\circ} \mathrm{C}$ for temperature, the relative humidity of $3.5 \%$, and an air velocity of $0.08 \mathrm{~m} / \mathrm{s}$, due to the significant effect of the building location. The Standardized Euclidean Distance (SED) analysis results are the optimum sensor positions that accurately, consistently, and have the optimum \% coverage representing the thermal condition at $1,1 \mathrm{~m}$ floor level. At the optimal positions, actual sensors are installed and proven to be valid results since sensors could detect thermal variables at the height of $1.1 \mathrm{~m}$ with SED validation values of $2.5 \pm 0.3,2.2 \pm 0.6,2.0 \pm 1.1$, for $R 15, R 33$, and $R 40$, respectively.

Key words: sensor placement, indoor thermal environment, euclidean distance, CFD model, monitoring system

\section{INTRODUCTION}

Electricity consumption that meets the thermal comfort demand is currently a strategic issue in the building sector. In Indonesia, energy consumption for the air conditioner (AC) system reached $20-30 \%$ in upper-middle-class residential buildings [1]. Meanwhile, in commercial buildings, $A C$ is estimated to cover more than half of electricity consumption. According to ASHRAE 55 , thermal comfort is a state of mind that describes someone's satisfaction toward the thermal environment, assessed through subjective evaluation [2]. Besides the human factor, thermal comfort is significantly influenced by environmental factors, such as the occupants' thermal environment conditions [3][4]. Every indoor environment has unique thermal environment characteristics that create a unique pattern of its thermal comfort needs. The uniqueness is due to the room's form and orientation, building envelope, outdoor thermal environment, and air conditioning system.

Good building management allows a building to produce an indoor environment with a high thermal comfort level but minimum energy use. A suitable management strategy is obtained by understanding the characteristics of the indoor thermal environment. Therefore, it is essential to have an indoor environment monitoring system. Environmental parameter sensors installed in the indoor environment will provide information that describes the indoor environment's characteristics. Table 1 shows several studies related to the indoor environment monitoring system. The accuracy of the monitoring results depends on the number of sensors installed. More sensors create a more accurate monitoring system representing the indoor environment's characteristics. Hence, Muriel et al. conducted a study in a church where sensors were distributed at several positions of different heights to obtain a detailed distribution of measured environmental parameters at all zones [5]. A similar study was found in [6]. However, the utilization of many sensors would raise the budget and difficulties of its installation, maintenance, and data processing to produce useful information [7].

Measurement errors of the environmental parameters caused by a limited number of sensors can be reduced by optimizing those sensors' placement. Several approaches are found in the previous research used to study sensor placement in indoor environments, aiming to obtain a measurement that could accurately represent the indoor environment's characteristics. Sensor placement, which considers the room's topology, was proposed by T. Seabrook [8] and cited by [9]. The topology strategy was used to place four sensors in 16 rooms in a building optimally and have the minimum number and useful sensors. The building topology was divided into six categories, which are line, star, circle, island, compact-grid, and dispersed-grid. Each of them has a suitable sensor placement location.

Using the thermal parameter values distribution to determine sensor placement can improve the measurement accuracy in representing the indoor environment characteristics. In the case of air quality monitoring systems, the distribution of air quality parameter values can be 
Table 1: Consideration perspective used for sensors' placements in the indoor environment monitoring system

\begin{tabular}{|c|c|c|c|c|c|c|c|}
\hline \multirow{2}{*}{ Ref. } & \multirow{2}{*}{$\begin{array}{c}\text { Authors } \\
\text { (Year) }\end{array}$} & \multicolumn{3}{|c|}{ Thermal comfort parameters } & \multirow{2}{*}{$\begin{array}{c}\text { Visual comfort } \\
\text { parameter } \\
\text { Illumination } \\
\end{array}$} & \multirow{2}{*}{$\begin{array}{c}\text { Air quality } \\
\text { parameter } \\
\text { Contaminant }\end{array}$} & \multirow{2}{*}{$\begin{array}{l}\text { Consideration perspective } \\
\text { for sensors placement }\end{array}$} \\
\hline & & Temperature & Humidity & Air velocity & & & \\
\hline [5] & $\begin{array}{l}\text { Muriel, } \\
\text { M.V.J., et al. } \\
(2014)\end{array}$ & o & o & & & ○ & $\begin{array}{l}\text { Sensors were spread in sev- } \\
\text { eral positions in the building } \\
\text { with different heights. }\end{array}$ \\
\hline [6] & $\begin{array}{l}\text { Rattanong- } \\
\text { phisat, W., } \\
\text { et. Al (2017) }\end{array}$ & o & ० & & & & $\begin{array}{l}\text { Sensors were placed in } \\
\text { several positions in the } \\
\text { building, but there is no fur- } \\
\text { ther detailed explanation. }\end{array}$ \\
\hline $\begin{array}{l}{[8]} \\
{[9]}\end{array}$ & $\begin{array}{l}\text { Seabrook, T } \\
\quad(2016)\end{array}$ & $\circ$ & & & & & $\begin{array}{l}\text { Sensors are placed } \\
\text { based on the room or } \\
\text { building topology. }\end{array}$ \\
\hline [10] & $\begin{array}{c}\text { Eliades, } \\
\text { D.G., (2013) }\end{array}$ & & & & & ० & $\begin{array}{l}\text { The placement of the } \\
\text { sensor is based on the } \\
\text { calculated impact of the } \\
\text { contaminant dispersion } \\
\text { event scenario. }\end{array}$ \\
\hline [11] & $\begin{array}{l}\text { Sharma, H. } \\
\text { (2019) }\end{array}$ & & & & & ० & $\begin{array}{l}\text { The method was based } \\
\text { on the operator move- } \\
\text { ment pattern (transfer op- } \\
\text { erator based framework). }\end{array}$ \\
\hline [12] & $\begin{array}{l}\text { Waeytens, J., } \\
\text { et al. (2018) }\end{array}$ & & & & & ० & $\begin{array}{l}\text { Based on the maximum source } \\
\text { location collected in the room. }\end{array}$ \\
\hline [15] & $\begin{array}{c}\text { Yogana- } \\
\text { than, D. } \\
(2018) \\
\end{array}$ & & & & ○ & & $\begin{array}{l}\text { Sensors placement using } \\
\text { K Means Clustering and } \\
\text { Pareto principal. }\end{array}$ \\
\hline [14] & $\begin{array}{l}\text { Lee, S., et } \\
\text { al. (2019) }\end{array}$ & ○ & & & & & $\begin{array}{l}\text { Sensor placement is based } \\
\text { on errors and entropy of } \\
\text { the measurement results. }\end{array}$ \\
\hline [16] & $\begin{array}{l}\text { Erickson, P., } \\
\text { et al. (2015) }\end{array}$ & ○ & $\circ$ & & & & $\begin{array}{l}\text { Sensor placement is based } \\
\text { on the Gaussian process. }\end{array}$ \\
\hline [17] & $\begin{array}{l}\text { Al-Kuwari, } \\
\text { M., et al. } \\
(2018)\end{array}$ & o & ○ & & o & $\circ$ & $\begin{array}{c}\text { Sensors were placed inside } \\
\text { the room, particularly under } \\
\text { the ceiling. }\end{array}$ \\
\hline [18] & $\begin{array}{l}\text { Zhou, P., et } \\
\text { al. I (2015) }\end{array}$ & o & & & & & $\begin{array}{l}\text { Sensors were placed at } \\
\text { the height of } 2 \mathrm{~m} \text { for safety } \\
\text { and to prevent interfer- } \\
\text { ence from its occupants. }\end{array}$ \\
\hline [19] & $\begin{array}{l}\text { Jin, Y., et al. } \\
\text { (2018) }\end{array}$ & $\circ$ & o & o & & & $\begin{array}{l}\text { Sensors were placed at the } \\
\text { height of } 1.6 \mathrm{~m} \text { (represent- } \\
\text { ing the environment around } \\
\text { the occupant's neck). }\end{array}$ \\
\hline [13] & $\begin{array}{l}\text { Yanti., R. J., } \\
\text { et al. (2019) }\end{array}$ & o & & & & & $\begin{array}{l}\text { Sensor placement is based } \\
\text { on the Gaussian process } \\
\text { analysis in variable values } \\
\text { distribution at the height of } \\
1.1 \mathrm{~m} \text { using CFD simulation. }\end{array}$ \\
\hline & This paper & ○ & ० & ○ & & & $\begin{array}{l}\text { Sensors placement based } \\
\text { on analysis of Standardized } \\
\text { Euclidean Distance in variable } \\
\text { values distribution at the height } \\
\text { of } 1.1 \mathrm{~m} \text { using CFD simulation } \\
\text { for several scenarios. }\end{array}$ \\
\hline
\end{tabular}


traced using contaminant dispersion scenarios [10], operator displacement patterns [11], and CFD simulations to localize the maximum source [12]. Meanwhile, in a thermal environment monitoring system, the thermal environment parameter value distribution can be obtained using CFD simulations, as done in [13].

Several methods could be used to analyze the environment parameters' value distribution. One can obtain the sensors' locations to provide the most accurate measured values, such as the calculation of errors and entropy of the measurement results [14], K-Means Clustering [15], and Gaussian process [16].

Another essential consideration is the occupants' activities. The installed sensors should not interfere with the occupants' activities, such as placing the sensors on the ceiling [17] or at the height of $2 \mathrm{~m}$ [18]. Hence, occupant activities' type and location will determine the number of sensors and their location. The value measured by the sensor is the value of the environmental parameter perceived by the occupants. Jin, Y. et al. [19] used a sensor at the height of $1.6 \mathrm{~m}$ on a thermal environment monitoring system in a city residence in China that represents the environment around the occupation's neck when performing an activity while standing.

Yanti, R. J., et al. [13] considered the thermal parameters value distribution at a height determined by its occupant activity in an educational building classroom. The students carried out studying activities while sitting and feeling the exposure to thermal conditions at the height of $1.1 \mathrm{~m}$ [2]. The data was obtained from a CFD simulation using IESVE software. Meanwhile, the method used to determine the sensor location from the distribution data is the Gaussian method. The study is limited in its value distribution data of the indoor thermal environment parameter, representing one thermal parameter and one room condition scenario. A condition that is not quite enough to describe the indoor thermal environment in the reviewed case. Furthermore, validation of the analysis results on the installed sensor is not yet discussed.

Given the discussion above, it can be assured that a method for finding the optimal thermal sensor placement is not yet available. Hence, the sensors data should obtain indoor thermal characteristics on the occupant's activity using three thermal parameters: temperature, relative humidity, and air velocity.

This paper discusses an analysis of optimal sensor placement positions by considering indoor thermal characteristics on the occupant's activity area. The indoor thermal environment characteristics are obtained from the data distribution of the thermal environment parameters value for several possible room conditions using CFD simulation by manipulating the outdoor climate and air conditioning system. The alternative sensors' positions are determined by considering installation convenience and occupant's safety. Utilizing the Standardized Euclidean Distance analysis, these positions are then selected for the best position using the distribution of the thermal parameters' values data at the activity zones. This method was chosen since it can present three dimensions of thermal environment parameters measurement, including temperature, humidity, and air velocity [20].

\section{MATERIALS AND METHODS}

The methodology used in this research consists of 3 stages: field observation, simulation of indoor thermal environment condition scenario using the CFD model, and sensors placement analysis, as shown in Figure 1. It will be further explained in the next section.

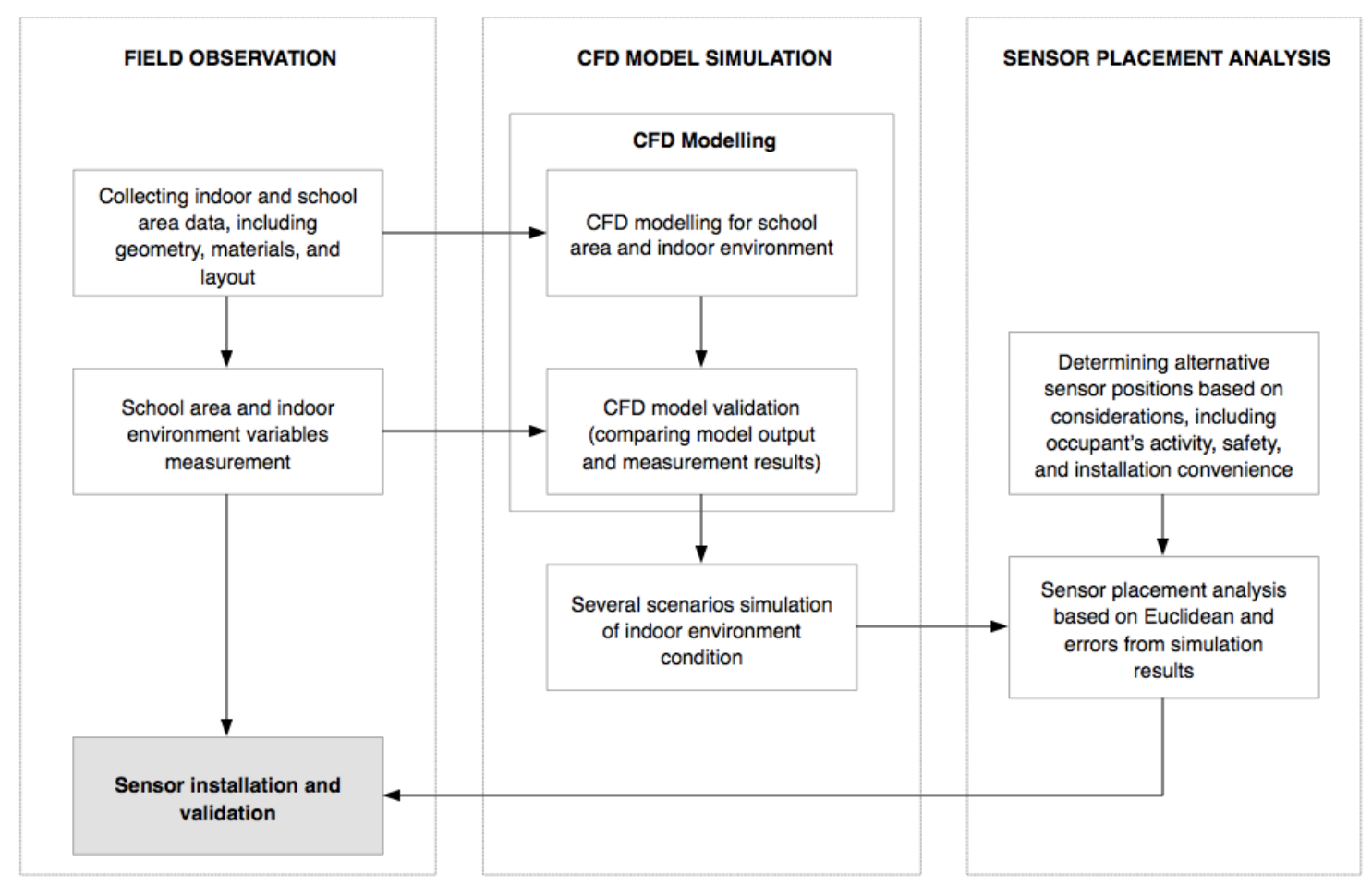

Figure 1: The methodology of research 


\section{Study case}

The case studied in this research is an educational building room in SMKN 3 Yogyakarta, a vocational high school located in Yogyakarta, Indonesia, with $30,000 \mathrm{~m}^{2}$ (Figure 2). Its buildings consist of old buildings with Yogyakarta-local design and new buildings with modern design. Generally, a classroom's geometry is typical with the same form and envelope. The air conditioning systems vary, but most of the classroom still use natural ventilation.

The three classrooms observed are R15, R33, and R40 classrooms (Figure $2 b$ ), which have typical materials and envelopes. R15 classroom's dimension is $15 \times 9 \mathrm{~m}^{2}$ with three Air Conditioners; meanwhile, R33 and R40 dimensions are $9 \times 9 m^{2}$ with natural ventilation. Their geometry is shown in Figure 3.

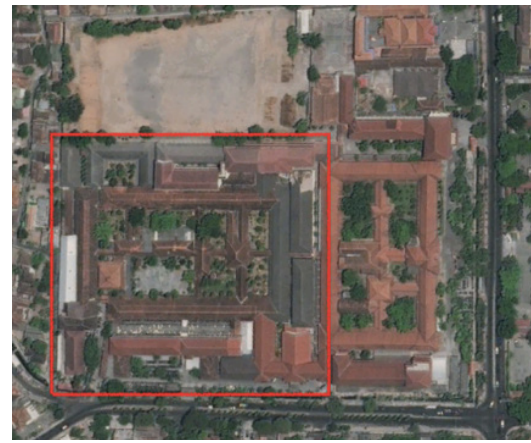

(a)

\section{CFD modeling}

The indoor thermal environment's characterization was conducted by analyzing the thermal environment parameters value for several possible room conditions using the CFD model results by manipulating the outdoor climate and air conditioning system. One of the essential factors in CFD modeling for the indoor thermal environment is the school area where rooms or buildings exist. The closer it is to the ground, where most of the living things are, the more the atmosphere's elements change rapidly. For example, the wind velocity will decrease as it gets closer to the ground due to friction and less air mixture. The climate in the land surface, called microclimate, is vertically estimated up to $1.5-2 \mathrm{~m}$ [21]. The main factors that influence microclimate are land surface conditions,

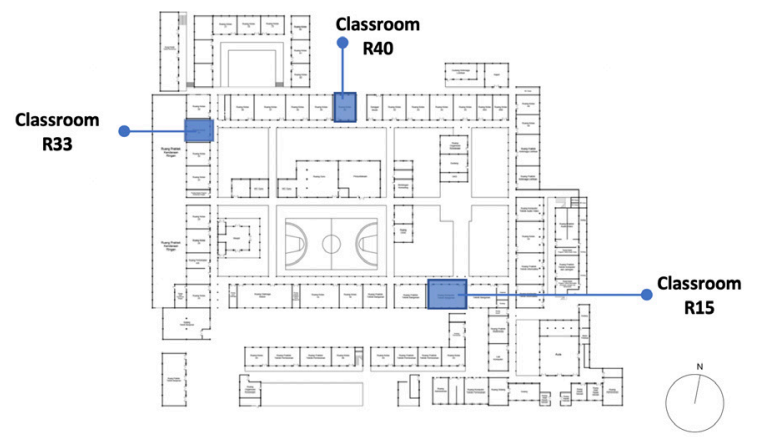

(b)

Figure 2: School area, (a), and rooms layout, (b), of SMKN 3 Yogyakarta
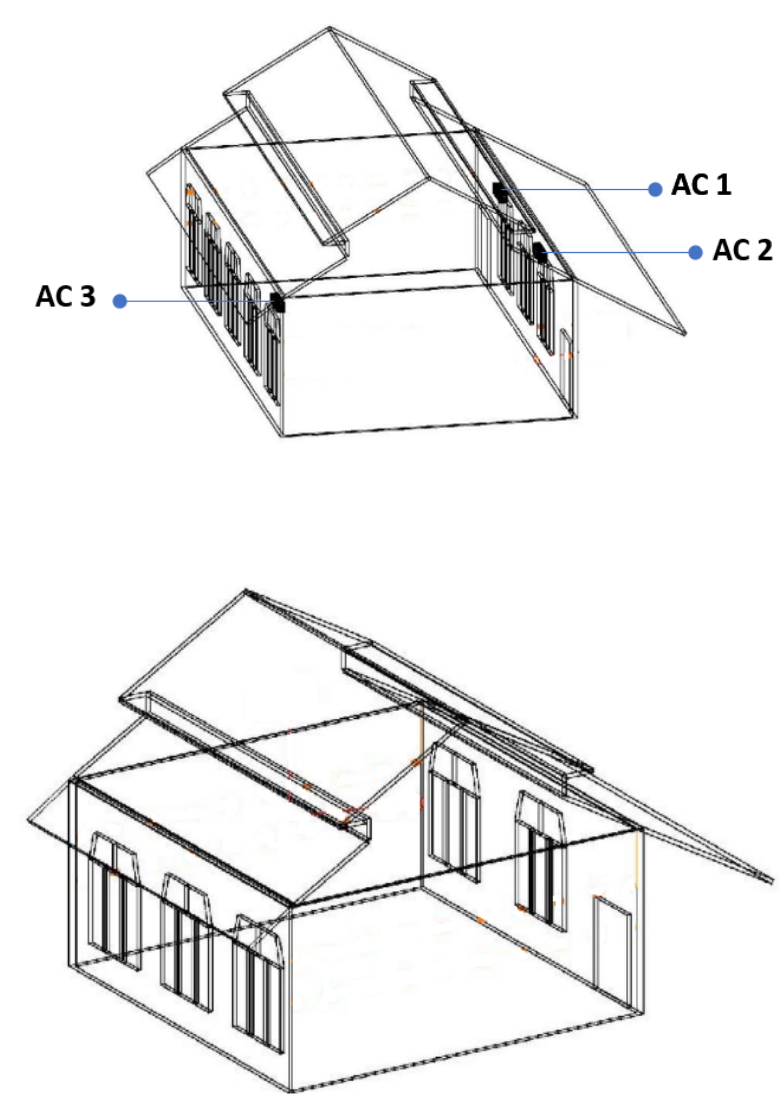

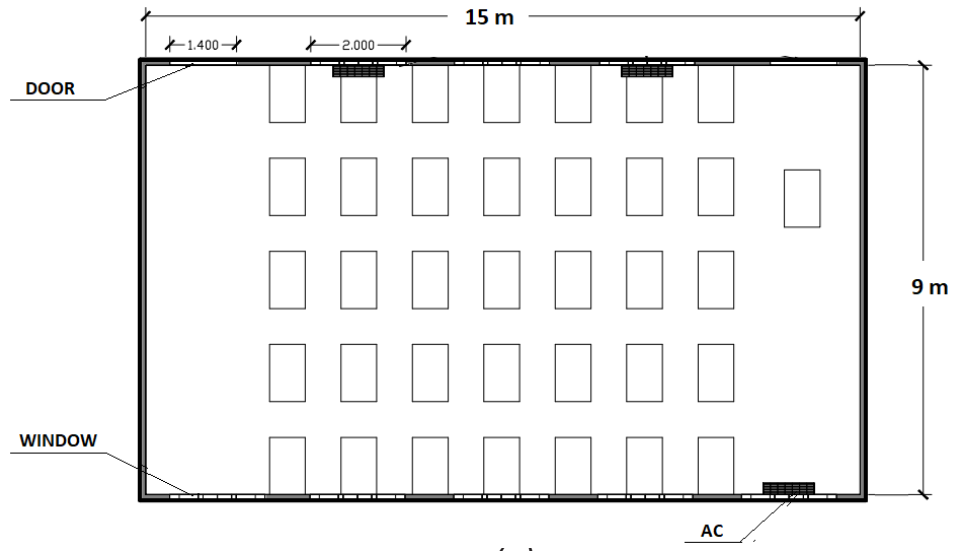

(a)

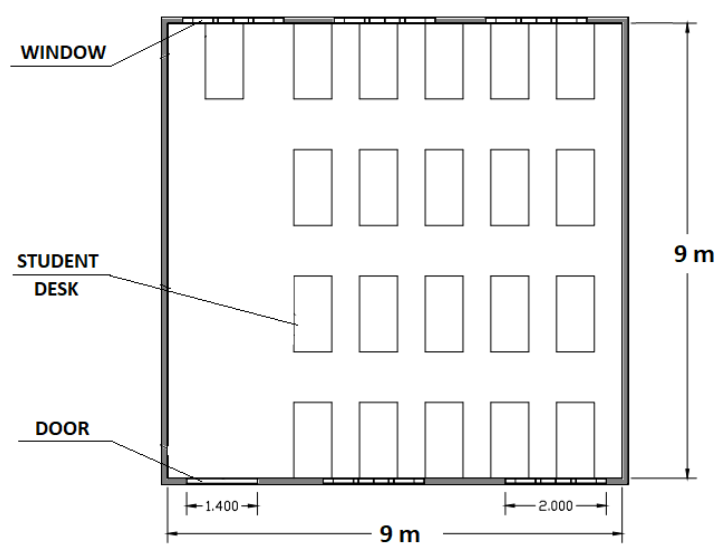

(b)

Figure 3: The geometry of (a) R15, (b) R33 and R40 
which includes soil, vegetation, and building infrastructures. These factors will affect the amount of solar radiation energy received and reflected on the surface and the air movement on the land surface. For an indoor environment with fixed form, orientation, envelope, function, and occupants, the indoor thermal environment would be influenced by microclimate and air conditioning systems. In this research, the indoor environment that consists of $\mathrm{R} 15, \mathrm{R} 33$, and R40 classrooms were modeled into the SMKN 3 Yogyakarta school area. The CFD model was built in software called Integrated Environmental Solution - Virtual Environment (IES-VE). IES-VE is a commercial software to perform a comprehensive building simulation needed by professionals to conduct a detailed environmental assessment and optimize building design [22] [23]. Three essential tools in IES-VE used to perform CFD simulation for gaining value distribution of indoor thermal environment parameters are ApacheSim, Microflow, and Suncast. ApacheSim is a dynamic thermal simulation program based on the mathematical model of heat transfer. Simulation in ApacheSim resulted in a resultant value of indoor thermal environment conditions that will change dynamically due to the alteration of disturbance from time to time. Microflow simulation is used to obtain the value distribution of indoor environment pa- rameters at certain heights, which requires CFD simulation. Meanwhile, Suncast is utilized to gain the irradiation flux value on the building envelope surface. Table 2 is the list of IES-VE settings used in the CFD modelling.

CFD simulation is a numerical solution related to three fluid flow conservation equations, including continuity, momentum, and energy conservation [24]. CFD model's quality can be shown from the convergence test and mass balance test. The convergence test is performed by reviewing the residual value that indicates an imbalance from the conservation equation. Meanwhile, the mass balance test is conducted to ensure if the system satisfies the mass conservation law in which the mass flow entering the system through an inlet should equal the mass flow leaving through an outlet.

Model validation was done by comparing the model results in IES-VE with field measurement. For the school area thermal environment model, the irradiation flux variable is represented by the building envelope's temperature [25]. Measurement of the building envelope temperature used a thermal camera on the R15, R33, and R40 classrooms' wall surfaces. Meanwhile, wind velocity measurement was done in several locations in the school area and measured at the height of $1.5 \mathrm{~m}$ and $3 \mathrm{~m}$. Model validation of the indoor thermal environment was

Table 2: IES-VE setting in CFD modeling

\begin{tabular}{|l|l|}
\hline Input & Yogyakarta (file .epw from meteonorm) \\
\hline Weather data & \multicolumn{2}{|l|}{} \\
\hline Parameter Model & $: 0.2585 \mathrm{~W} / \mathrm{m}^{2} \mathrm{~K}$ \\
\hline Roat transfer coefficient & $: 2.4910 \mathrm{~W} / \mathrm{m}^{2} \mathrm{~K}$ \\
Internal wall (plaster-brick-plaster) & $: 3.078 \mathrm{~W} / \mathrm{m}^{2} \mathrm{~K}$ \\
External wall (plaster-brick-plaster) & $: 2.2967 \mathrm{~W} / \mathrm{m}^{2} \mathrm{~K}$ \\
Door & \\
Floor & $: 0.6518 \mathrm{~W} / \mathrm{m}^{2} \mathrm{~K}$ \\
R15 (concrete tiles - synthetic carpet) & $: 0.8949 \mathrm{~W} / \mathrm{m}^{2} \mathrm{~K}$ \\
R33-R40 (concrete tiles) & $: 3.8502 \mathrm{~W} / \mathrm{m}^{2} \mathrm{~K}$ \\
Grille ventilation & $: 6.3962 \mathrm{~W} / \mathrm{m}^{2} \mathrm{~K}$ \\
\hline Clear glass window & $3 \mathrm{D}$ \\
\hline Room geometry & \\
\hline Location & $6.97^{\circ}$ South \\
\hline Latitude & $110.37^{\circ}$ East \\
\hline Longitude & $113 \mathrm{~m}$ \\
\hline Elevation & Normal \\
\hline Wind exposure & Suburbs \\
\hline Terrains type & Top hung \\
\hline Window & Side hung \\
\hline Door & \\
\hline Output & $:$ Wind velocity, Irradiation flux \\
\hline School area thermal environment & $:$ Temperature, Relative humidity, Air velocity \\
\hline Indoor thermal environment &
\end{tabular}


conducted for the model output variables, including air temperature, humidity, and air velocity. Those three variables measurement was done in 5 measurement points inside the classrooms at the height of $1 \mathrm{~m}, 2 \mathrm{~m}$, and $3 \mathrm{~m}$.

\section{Simulation of thermal environment condition scenario}

The thermal environment model's simulation aims to obtain the distribution of thermal environment parameter values data on occupants living zones. In our model, students as occupants are doing learning activities in a classroom while experiencing thermal conditions at the height of $1.1 \mathrm{~m}$ [2]. Several input scenarios are given to obtain simulation results representing the characteristics of the indoor thermal environment. Table 3 shows the outdoor climate and air conditioning input scenarios by varying the IES-VE weather data settings. The four different dates represent the sun's annual path from the equator towards $23.5^{\circ} \mathrm{N}$ and $23.5^{\circ} \mathrm{S}$.

\section{Sensors placement analysis}

Two steps of approaches are used to determine thermal sensor locations. First, the method is considered an alternative position where the sensor installation is convenient and ensures the occupant's safety. Secondly, the sensor locations were decided by representing the indoor thermal environment (temperature, humidity, and air velocity) at the height of $1.1 \mathrm{~m}$. The representation level is described by the Euclidean distance between the installed sensor measured value and the thermal condition measurement value at the height of $1.1 \mathrm{~m}$, as shown in Figure 4.

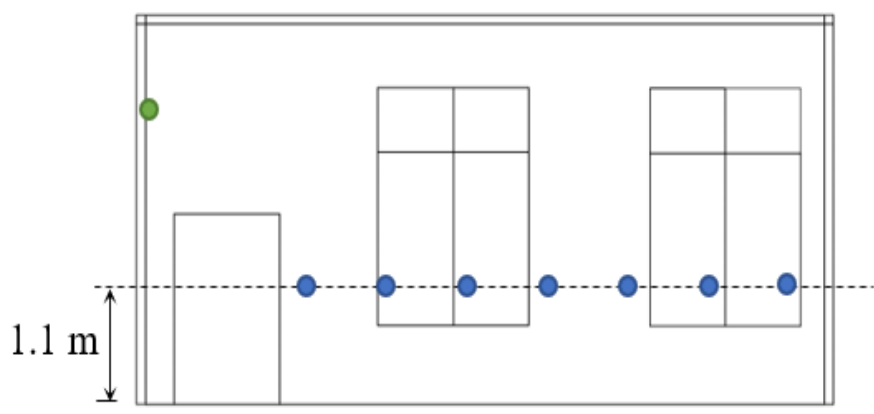

Figure 4: Sensors and the represented thermal condition positions

The Euclidean distance is the conventional distance measurement commonly used for data classification due to its simplicity and applications. If there are two vectors of $j$-dimension, namely $x$ and $y$, the Euclidean distance, $d_{x, y}$, between these two vectors can be formulated,

$d_{x, y}=\sqrt{\sum_{j=1}^{J}\left(x_{j}-y_{j}\right)^{2}}$

Equation (1) is used to obtain the representation level of the thermal conditions at the height of $1.1 \mathrm{~m}, x$, with the results of sensor measurement at the alternative position, $y$, for three dimensions of thermal condition measurement, including air temperature, $t_{a}$, humidity, $R H$, and air velocity, $v_{a}$, in the indoor environment. Thus, resulted in Equation (2),

$d_{x, y}=\sqrt{\left(x_{j}-y_{j}\right)^{2}+\left(x_{R H}-y_{R H}\right)^{2}+\left(x_{v_{s}}-y_{v_{a}}\right)^{2}}$

A problem would arise because the measurement's three dimensions are three different variables with three different units. Therefore, a data transformation is required to

Table 3: Input variables variation in CFD model simulation of the school area and indoor environment

\begin{tabular}{|c|c|c|c|}
\hline \multirow{2}{*}{ Classroom } & \multicolumn{2}{|c|}{ Model input variable } & \multirow{2}{*}{ Output Variable } \\
\hline & Building outdoor climate & Indoor air conditioning & \\
\hline $\begin{array}{l}\text { R15 Classroom } \\
\text { (16 scenarios) }\end{array}$ & $\begin{array}{l}\text { Weather data date setting } \\
\text { on: } \\
\text { M-21 March } \\
\text { J-21 June } \\
\text { S-23 September } \\
\text { D-22 December }\end{array}$ & $\begin{array}{c}\text { AC ON/OFF: } \\
\text { AC OFF } \\
\text { AC0-1 AC ON } \\
\text { AC2-2 AC ON } \\
\text { AC3-3 AC ON }\end{array}$ & $\begin{array}{l}\text { School area thermal environment } \\
\text { parameters: }\end{array}$ \\
\hline $\begin{array}{l}\text { R33 Classroom } \\
\text { (12 scenarios) }\end{array}$ & $\begin{array}{l}\text { Weather data date setting } \\
\text { on: } \\
\text { M-21 March } \\
\text { J-21 June } \\
\text { S-23 September } \\
\text { D-22 December }\end{array}$ & $\begin{array}{l}\text { Window Opening } \\
\text { J0-Closed } \\
\text { J1-Opened } \\
\text { Door Opening } \\
\text { J0-Closed } \\
\text { J1-Opened }\end{array}$ & $\begin{array}{l}\text { Distribution of solar flux irra- } \\
\text { diation on classroom external } \\
\text { envelope. } \\
\text { - Wind velocity distribution at } \\
\text { the height of } 1.5 \mathrm{~m} \text {. } \\
\text { Indoor thermal environment pa- } \\
\text { rameters: }\end{array}$ \\
\hline $\begin{array}{l}\text { R40 Classroom } \\
\text { (12 scenarios) }\end{array}$ & $\begin{array}{l}\text { Weather data date setting } \\
\text { on: } \\
\qquad \begin{array}{c}\text { M-21 March } \\
\text { J-21 June } \\
\text { S-23 September } \\
\text { D-22 December }\end{array}\end{array}$ & $\begin{array}{l}\text { Window Opening } \\
\text { J0-Closed } \\
\text { J1-Opened } \\
\text { Door Opening } \\
\text { J0-Closed } \\
\text { J1-Opened }\end{array}$ & $\begin{array}{l}\text { Distribution of temperature, humid- } \\
\text { ity, and air velocity at the height of } \\
1.1 \mathrm{~m} .\end{array}$ \\
\hline
\end{tabular}


balance the data distribution. One of the easiest ways is making variants from the three distributions equal to 1 , and placing the distribution center in the mean value equals 0 . The data transformation will produce a standardized value [20],

$$
\text { standardized value }=\frac{\text { original value }- \text { mean value }}{\text { standard deviation }}
$$

Thus, Equation (2) could be written into Standardized Euclidean Distance (SED),

$$
d_{x, y}=\sqrt{\left(\frac{x_{t_{a}}-y_{t_{a}}}{S_{t_{a}}}\right)^{2}+\left(\frac{x_{R H}-y_{R H}}{S_{R H}}\right)^{2}+\left(\frac{x_{v_{a}}-y_{v_{a}}}{S_{v_{a}}}\right)^{2}}
$$

Where $S$ is the standard deviation calculated for all data in each dimension or measurement variable, the mean value is not included because it is eliminated in Equation (4). Sensor placement analysis based on SED described in this paper is using IES-VE model output data. Thermal environment parameter data at the height of $1.1 \mathrm{~m}, x$, and at sensor's position, $y$, are gained from IES-VE model output data simulated with scenario shown in Table 3. The analysis was conducted by observing SED's mean and standard deviation from all simulation scenarios and SED scenarios within the tolerance range. Each SED's mean and standard deviation would show the accuracy and consistency of sensor measurement results in an alternative position. Meanwhile, SED's scenarios within the tolerance range show the sensor's coverage level in an alternative position. Based on those three values, a sensor position with the best performance is selected, representing the indoor thermal environment at the height of $1.1 \mathrm{~m}$.

\section{Implementation and validation of sensor placement analysis result}

The sensor placement analysis results discussed in section 2.4 is then implemented into a real indoor environment. The output of the installed sensors is compared with the result of thermal condition measurement at the height of $1.1 \mathrm{~m}$ as a validation technique. Both data are taken at the same time.

\section{RESULTS AND DISCUSSION}

\section{CFD model for school area and indoor thermal environment}

Geometry models of the school area and indoor thermal environment are shown in Figure 5. Residual values indicate the quality of the CFD model's numerical results from the convergence test in Figure 6. The simulation result had reached convergence where there is no change, which means additional iteration does not change the quality with the residual value less than $10^{-2}$. It could be achieved through 6000, 1200, and 1000 iterations for each school area, R15 classroom, and R33/R40 classroom. The mass balance test shows that mass flow entering the system through an inlet, and the mass flow leaving through an outlet equals $0 \mathrm{~kg} / \mathrm{s}$.

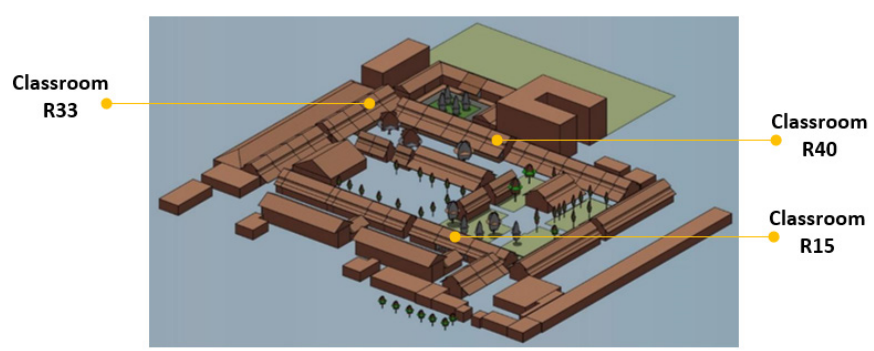

(a)

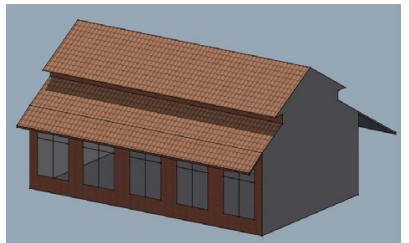

(b)

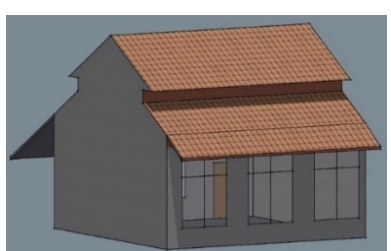

(c)
Figure 5: Geometry models of (a) school area, (b) R15 classroom, (c) R33 and R40 classrooms using IES-VE software

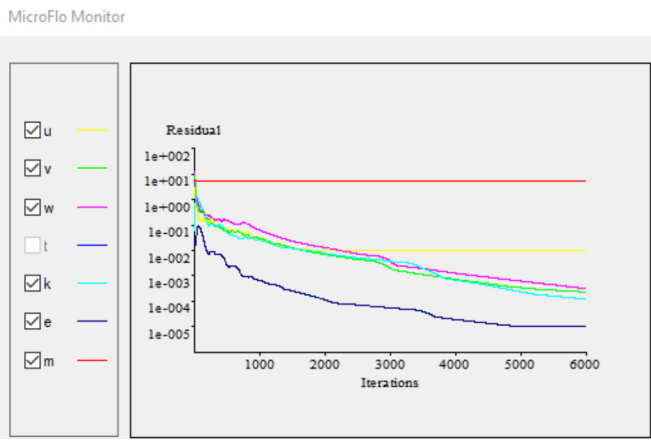

(a)

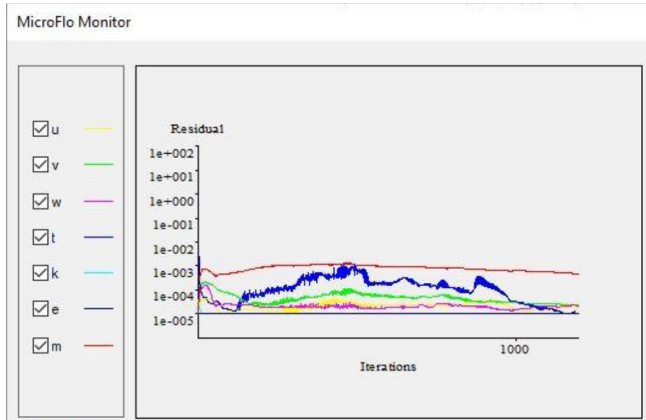

(b)

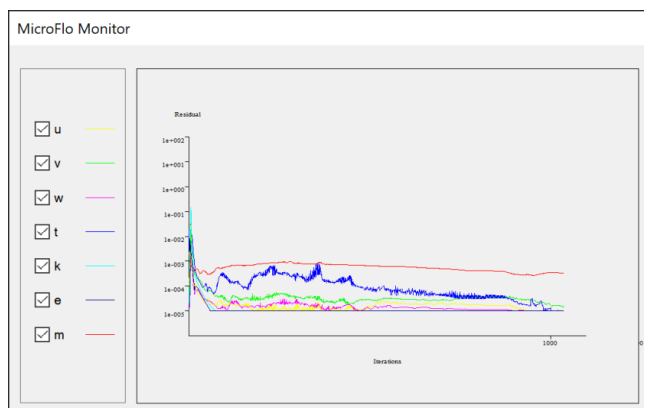

(c)

Figure 6: Residual values from model simulations of (a) school area, (b) R15 classroom, (c) R33 and R40 classrooms 
Table 4: RMSE between simulation and field measurement results

\begin{tabular}{|c|c|c|c|c|}
\hline $\begin{array}{c}\text { Thermal environment } \\
\text { parameter }\end{array}$ & School Area & R15 & R33 & R40 \\
\hline Envelope temperature $\left({ }^{\circ} \mathrm{C}\right)$ & 1.7 & - & - & - \\
\hline Air temperature $\left({ }^{\circ} \mathrm{C}\right)$ & - & 0.3 & 0.8 & 0.2 \\
\hline Relative humidity $(\%)$ & - & 0.6 & 3.5 & 3.0 \\
\hline Air/wind velocity $(\mathrm{m} / \mathrm{s})$ & 0.60 & 0.00 & 0.08 & 0.05 \\
\hline
\end{tabular}

Model validation is conducted by comparing model output values with field measurement values (Figure 7). RMSE values show the difference between these two values, as shown in Table 4. Several factors cause the difference between model output with field measurement, including the simulation weather data that is not quite the same with the weather during the field measurement, simplification of vegetation model in the school area, and a difference in occupants' activity on-site and simulation.

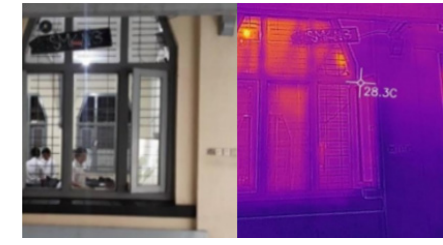

(a)

\section{Characterization of thermal environment through CFD model simulation results}

CFD model simulation results of the thermal environment in R15, R33, and R40 classrooms for all scenarios are shown in Figure 8. Thermal environment parameters include temperature, humidity, and air velocity at the height of $1.1 \mathrm{~m}$. The occupants will perceive thermal conditions at this height in a sitting position.

The indoor thermal environment is significantly influenced by the school area's thermal environment, including fabric, surface cover, dimension, structure of building composition, and human activities [26]. The dominant thermal environment parameters that affect the indoor thermal environment are irradiation flux on the building envelope and wind velocity on its surrounding area. Indoor heat gain is contributed by conduction on opaque surfaces due to the outdoor irradiation flux or radiation through oblique surfaces. Meanwhile, wind infiltration and exfiltration through small openings create changes

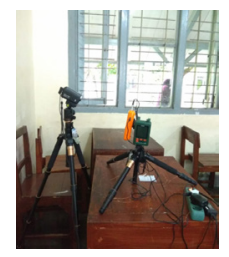

(b)

Figure 7: Model validation through building's wall temperature measurement using thermal camera (a) and indoor thermal environment parameter (b)
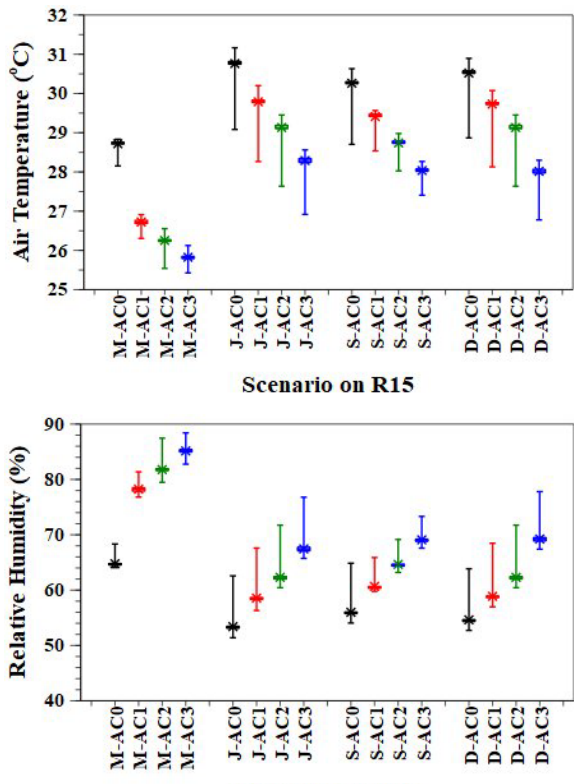

Scenario on R15

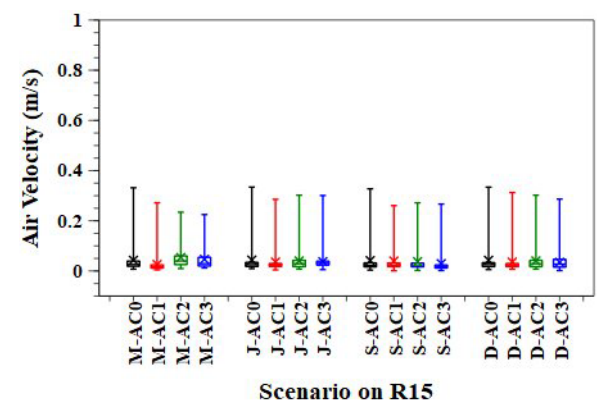

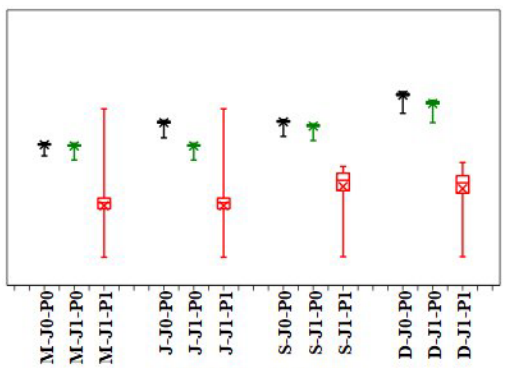

Scenario on $\mathbf{R 3 3}$
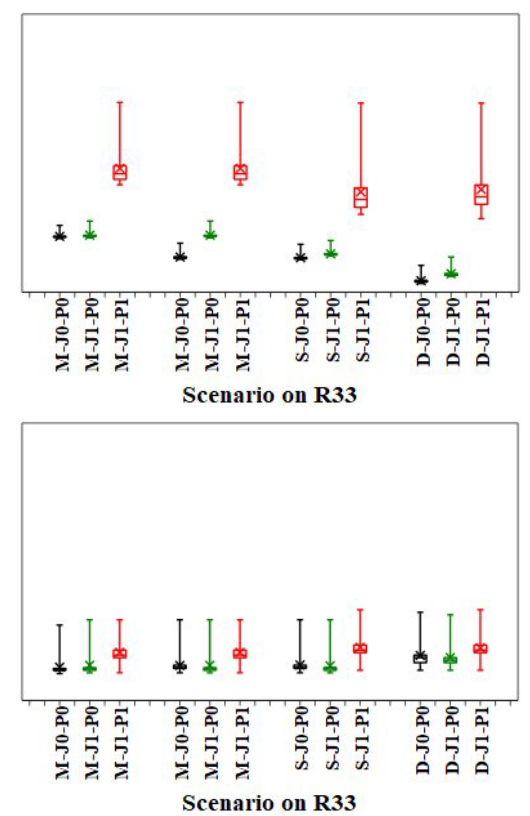
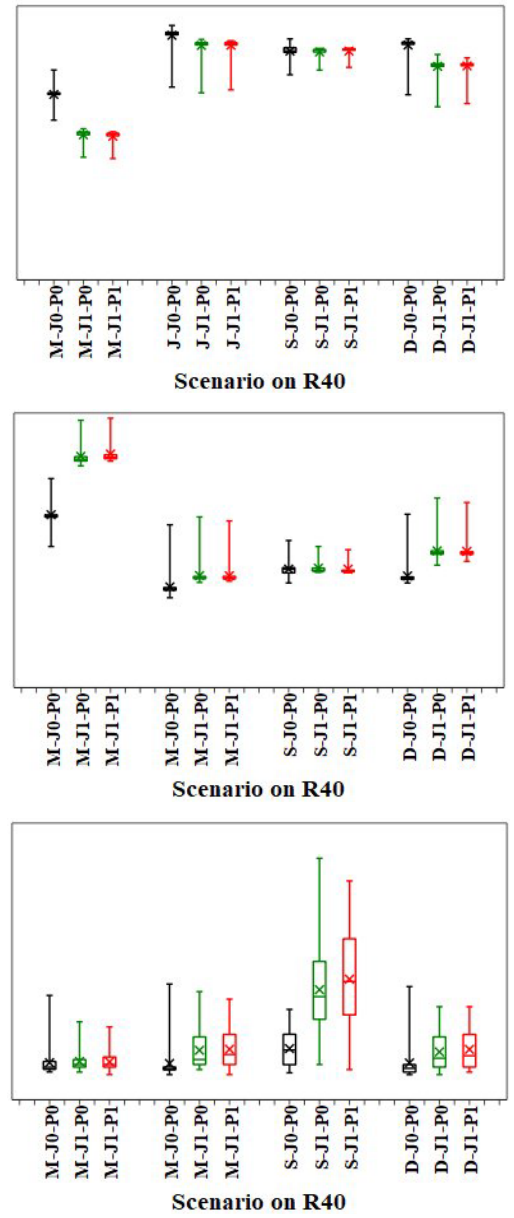

Figure 8: CFD model simulation result of thermal environment in $R 15, R 33$, and $R 40$ for all scenarios 
in the airflow rate. Both processes shall influence the room temperature, humidity, and air velocity.

Figure 9. shows the value of roof and wall irradiation flux in each classroom. The roof and wall irradiation flux in R15, $\mathrm{R} 33$, and R40 classrooms increases during the one-year climate cycle, with a maximum value of $310 \mathrm{~W} / \mathrm{m}^{2}$, and it happens in December. It is influenced by the sun's annual path and Yogyakarta city position, located at $6.97^{\circ} \mathrm{S}$ and $110.37^{\circ} \mathrm{S}$. R15, R33, and R40 classrooms use roofs and walls with the same materials but have different dimensions and structures due to other school areas' positions. A triangular prism-shaped roof, orientation, and shading caused by the structure's density will affect the irradiation flux amount on the classroom's roof and walls. The northsouth orientation of R15, without shading, and a relatively dense structure makes R15 has the highest roof and wall irradiation flux than two other rooms, with an average of $238 \mathrm{~W} / \mathrm{m}^{2}$ and $213 \mathrm{~W} / \mathrm{m}^{2}$, respectively, for the ceiling and walls. The roof and wall irradiation flux of R33 is the lowest among the two other rooms, with an average of 175 $\mathrm{W} / \mathrm{m}^{2}$ and $176 \mathrm{~W} / \mathrm{m}^{2}$ for roof and walls, respectively. The orientation in the east-west direction causes the roof side to get maximum solar radiation exposure alternately. The massive structure of R33 in the school area causes the wall to experience shading from the surrounding buildings.

Shading also occurs on the roof of R40 by the second-floor building from the north side. It is shown by the exposure time distribution in Figure 10, where the roof of R40 is not exposed to full solar radiation. With a north-south orientation, the irradiation flux value on the roof of R40 is not as high as $\mathrm{R} 15$, with an average of $176 \mathrm{~W} / \mathrm{m}^{2}$. The relatively dense structure causes the wall irradiation flux of R40 to be higher than R33, with an average of $186 \mathrm{~W} / \mathrm{m}^{2}$.

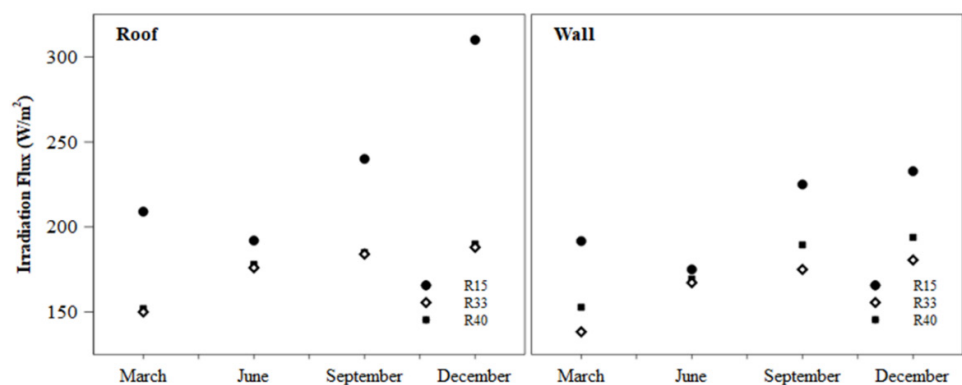

Figure 9: The average of irradiation flux on the roof and wall of R15, R33, and R40 classrooms

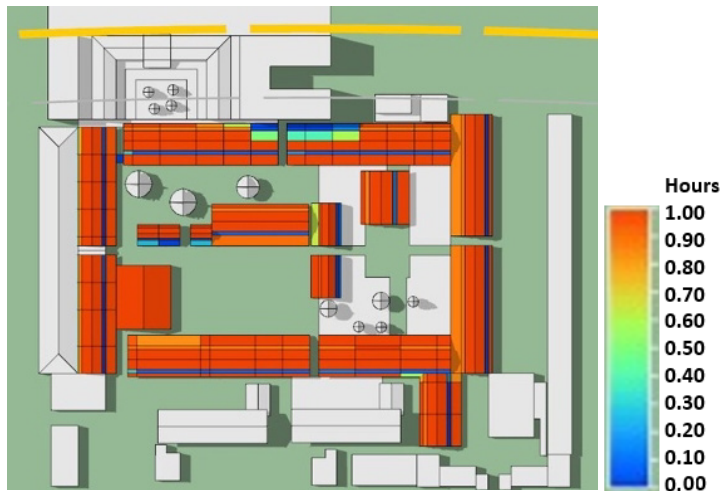

Figure 10: Exposure hour distribution that shows shading on R40's roof by the northern building
The roof and wall irradiation flux's value will affect the air temperature and humidity in the classroom, shown in Figure 8. The air temperature in R33 is the lowest compared to R15 and R40 due to the low irradiation flux value of R33's roof and walls. Meanwhile, although the wall and roof flux irradiation in R15 is the highest, the wider area causes the air temperature in the R15 classroom to be lower than in R40 classrooms. In the condition without $\mathrm{AC}$, all doors and windows are closed in all rooms and $\mathrm{R} 15$ 's $\mathrm{AC}$ is off, the air temperature in the classrooms reaches $30.7 \pm 0.2^{\circ} \mathrm{C}, 28.9 \pm 0.1^{\circ} \mathrm{C}$, and $30.9 \pm 0.3^{\circ} \mathrm{C}$, for $\mathrm{R} 15, \mathrm{R} 33$, and $\mathrm{R} 40$, respectively. The highest average air temperature is reached in June, during the dry season. Except for R33, due to heat stored from the adjacent workshop building (east of the R33), the highest average air temperature happens in December. The value of air humidity in the indoor environment is inversely proportional to the air temperature. The higher the air temperature at the same location and time, the lower the air humidity is [27]. The highest indoor air humidity values are achieved in March of $62.3 \% \pm 3.1 \%$ and $82.5 \% \pm 1.4 \%$ for R33 and R40, respectively, with the doors and windows open, and in March for R15, which reached 85.3\% $\pm 0.8 \%$ when all the air conditioners are on.

Figure 11 shows one of the dominant directions $\left(330^{\circ}\right)$ of the wind velocity distribution at the school area and the average initial rate of $2 \mathrm{~m} / \mathrm{s}$. Wind velocity in the school area will affect the indoor thermal condition for natural-

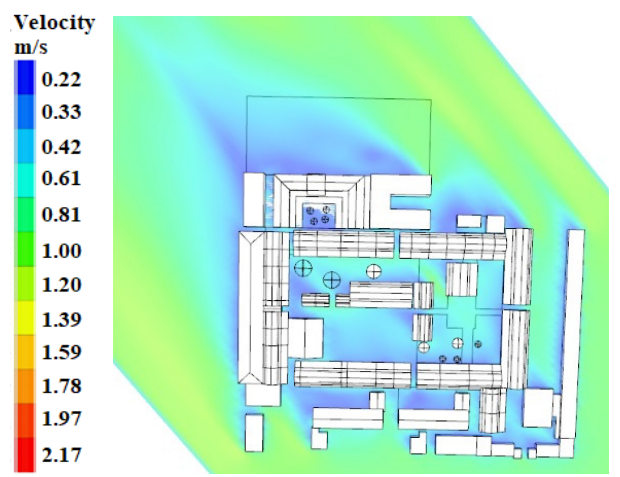

(a)
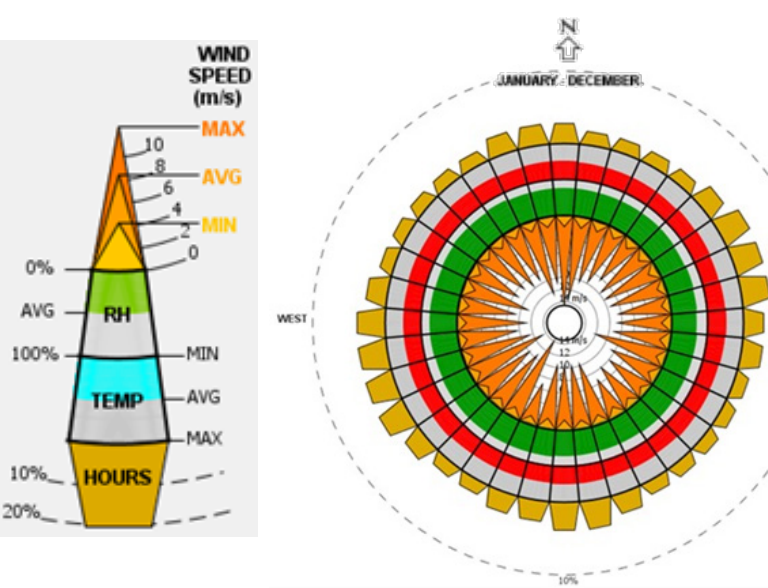

(b)

Figure 11: Distribution of school area's wind velocity in the direction of $320^{\circ}$ and average initial rate of $2 \mathrm{~m} / \mathrm{s}$ (a), according to Windrose diagram of SMKN 3 Yogyakarta (b) 


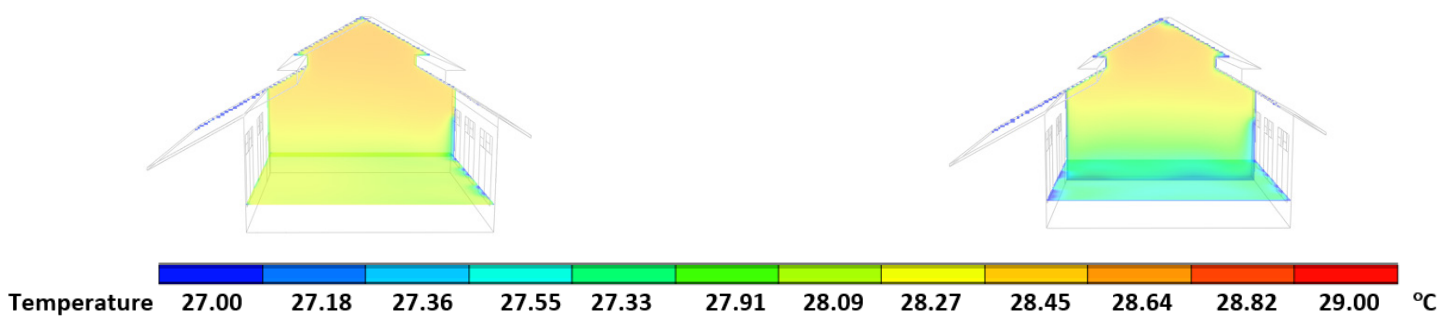

(a)

(b)

Figure 12: Distribution of air temperature in (a) R33 and (b) R40 with opened door and windows

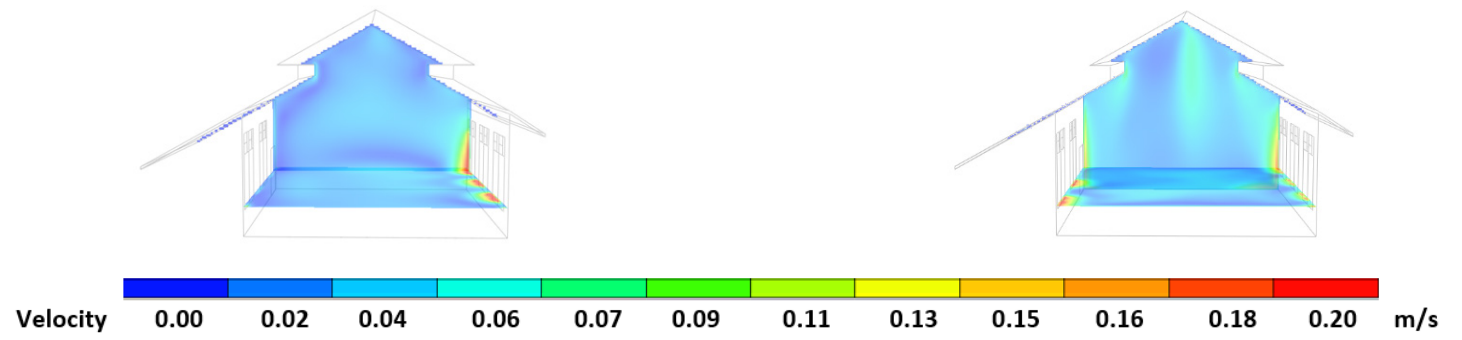

(a)

(b)

Figure 13: Distribution of air velocity in (a) R33 and (b) R40 with opened doors and windows

ly ventilated rooms (R33 and R40). Figure 8 shows that additional openings could decrease the indoor air temperature. Orientation and the number of openings would influence the indoor temperature and air velocity. R33 classroom has openings on the west and east walls. The west wall is attached to another building. The wind velocity in front of R33 at $1.5 \mathrm{~m}$ above the ground level is up to $0.5 \mathrm{~m} / \mathrm{s}$, while the indoor air velocity is $0.07 \pm 0.05$ $\mathrm{m} / \mathrm{s}$. Wind entering the east opening could not compensate for the heat or cold effect from the building attached on the west side. It creates temperature and humidity variations that are relatively high when the windows and doors of R33 are opened. A different condition happens in R40. Wind velocity at $1.5 \mathrm{~m}$ reaches $0.3 \mathrm{~m} / \mathrm{s}$ from the north and $0.4 \mathrm{~m} / \mathrm{s}$ from the south. The wind enters from both openings in north and south, causing relatively higher air velocity variations in R40 than in R33, which is $0.12 \pm 0.14 \mathrm{~m} / \mathrm{s}$ with a relatively even air temperature distribution. The distribution of temperature and air velocity in R33 and R40 is shown in Figures 12 and 13.

\section{Sensors placement analysis results}

Figure 14 shows an alternative position for installing sensors in the indoor environment. There are 20 alternative sensor positions in each room, with an equal distance of $1 \mathrm{~m}$ on the front (D) and rear (B) windowless walls. Determining alternative sensor positions should consider avoiding interference with occupants' activity, positions unreachable by occupants, and convenient installation.

The critical success of analysing sensor placement based on the indoor thermal environment characterization is how far the scenarios can represent all possible conditions in the real situation. Figure 15 shows the distribution of SED calculation results for all simulation scenarios in each alternative sensor position. In R15 and R40, a significant deviation occurs in the alternative sensor position 1 or 10 near the AC placement and the opening (see Figure 13), with values reaching $8.1 \pm 2.6$ and $6.7 \pm 1.4$ for R15 and R40, respectively. For the R33 classroom, the largest variation in SED value among other classrooms happens caused by variations in thermal conditions at $1.1 \mathrm{~m}$ due to heat stored from the workshop building attached to the east side of R33.
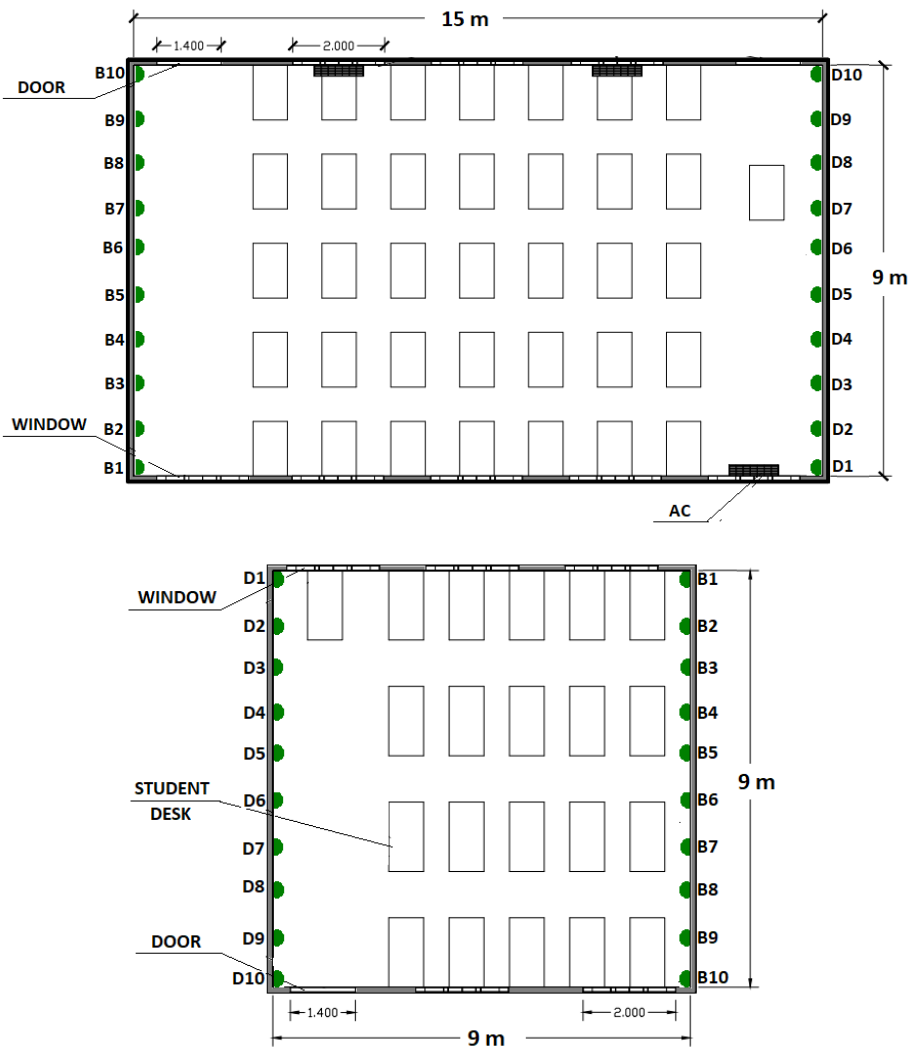

Figure 14: Alternative installed sensor positions in the indoor environment 

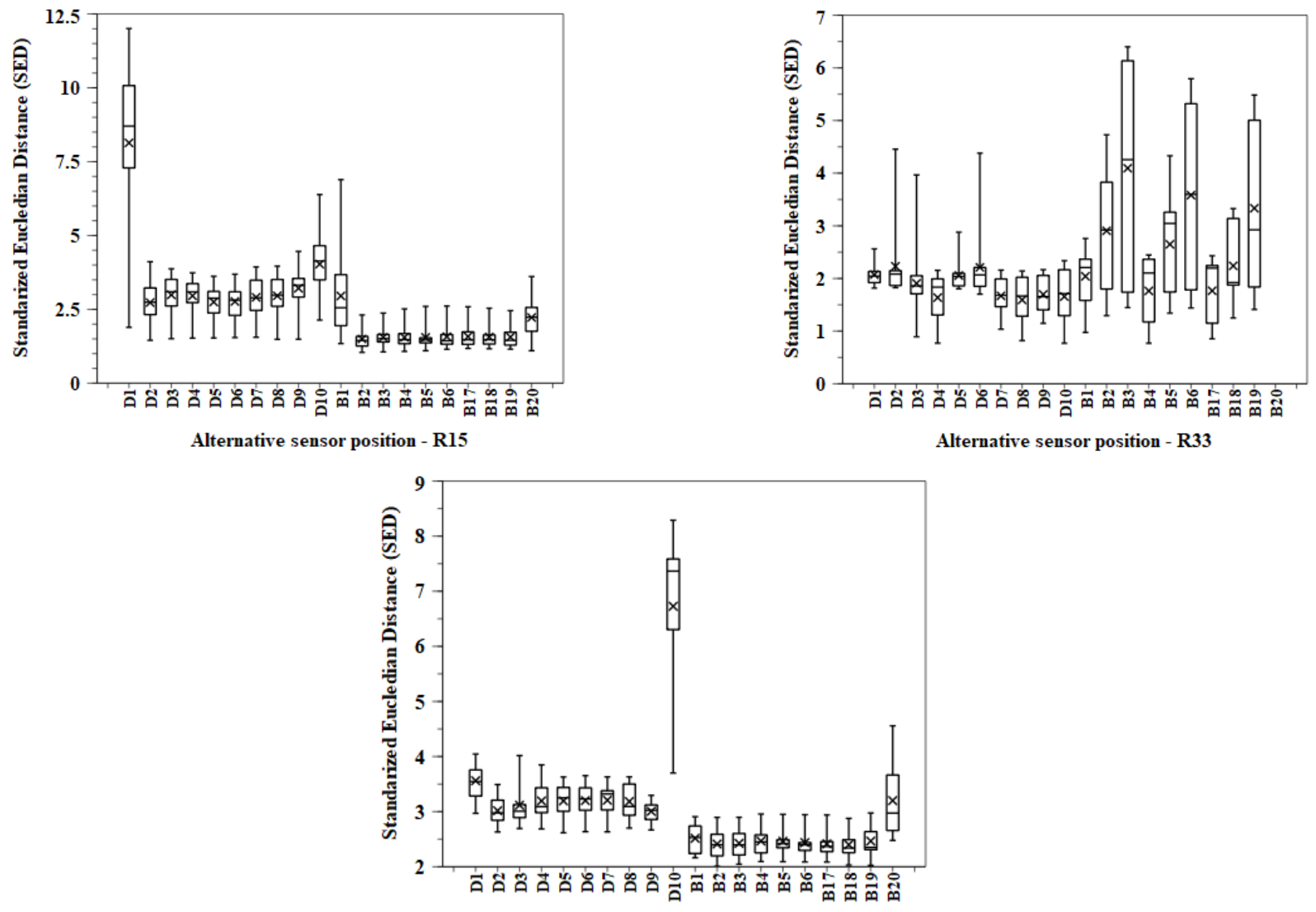

Alternative sensor position - R40

Figure 15: Distribution of SED calculation results data for all simulation scenarios in each alternative sensor position

Figure 16 shows SED's mean and SED's standard deviation and the percent (\%) coverage for all simulation scenarios. Percent (\%) coverage states the number of scenarios with the distribution of thermal environment

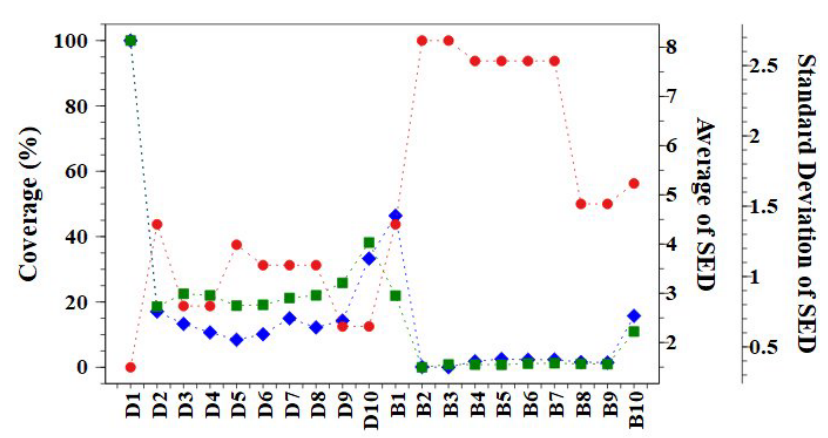

Alternative sensor position - R15 parameters represented by the sensor's value at an alternative position. The smallest mean and standard deviation of the SED indicate the accuracy and consistency of sensor measurements at an alternative position. In this
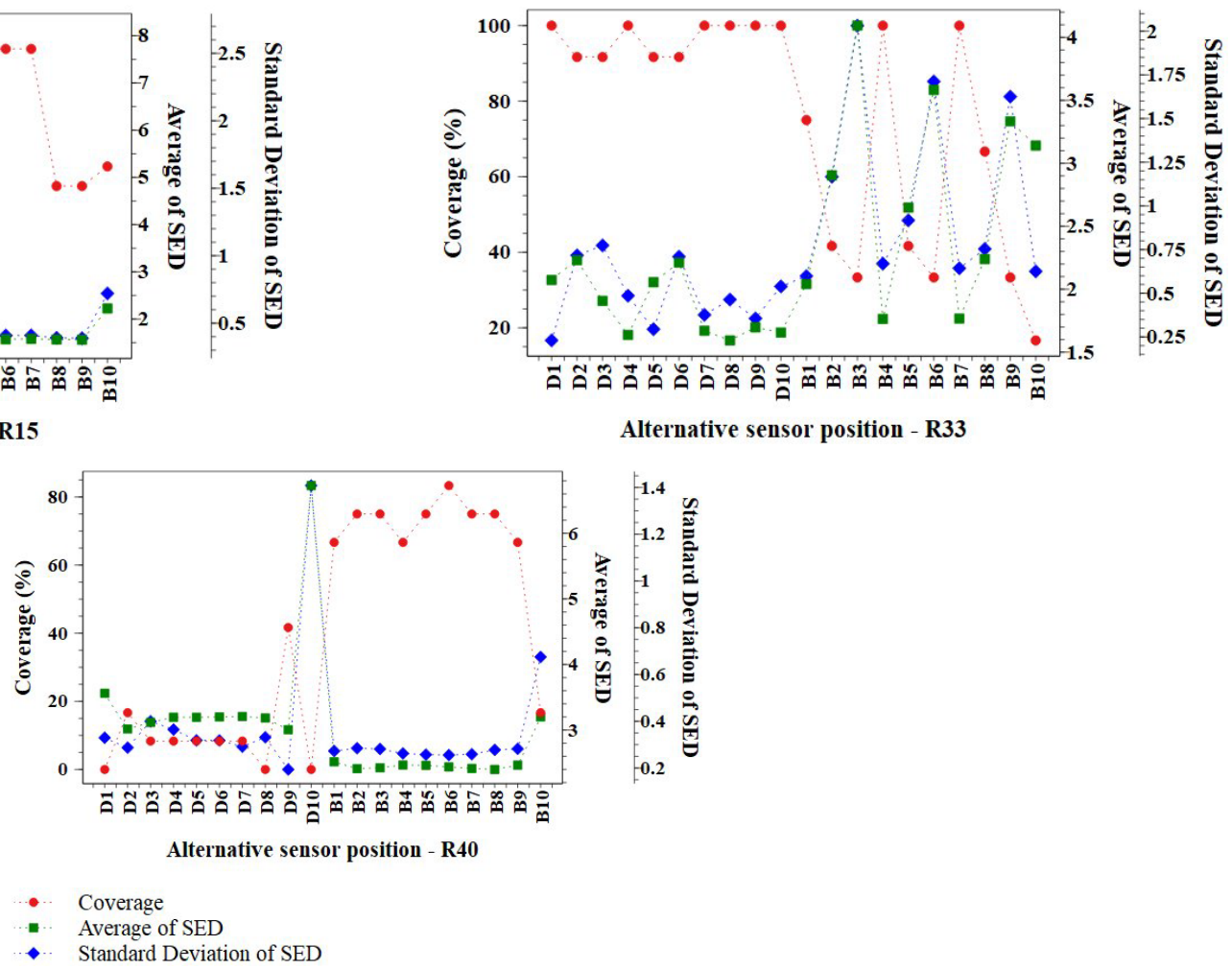

Figure 16: SED's mean and standard deviation for all simulation scenarios and \% coverage of an alternative sensor position 
Table 5: Measuring instrument specifications installed in the selected position

\begin{tabular}{|c|c|c|c|c|c|}
\hline Measured variables & Measuring instrument Name/Model & Model & Range & Accuracy & Resolution \\
\hline Air temperature & 1-Wire Parasite-Power Digital Thermometer & DS18B20 & $(-55)-100^{\circ} \mathrm{C}$ & $\pm 0.50{ }^{\circ} \mathrm{C}$ & $0.01^{\circ} \mathrm{C}$ \\
\hline Relative humidity & Humidity and Temperature Sensor IC & SHT20 & $0-100 \%$ & $\pm 3 \%$ & $0.7 \%$ \\
\hline Air/wind velocity & Hot Wire Anemometer & Lutron & $0-20 \mathrm{~m} / \mathrm{s}$ & $5 \%$ & $0.1 \mathrm{~m} / \mathrm{s}$ \\
\hline
\end{tabular}

paper, the SED tolerance value is set at 2.5. The thermal environment parameters distribution of a scenario can be represented by the sensor's data at an alternative position if it has an average SED value of less than 2.5 .

\section{Validation of sensor placement results}

Figure 17 shows the installed sensor in the R40 classroom based on the analysis results in 3.3. Similar sensor installations are also done for R15 and R33. The sensor specifications are shown in Table 5. Figure 18 shows the distribution of SED values between the thermal environment parameter from 5 locations of equal distance at $1.1 \mathrm{~m}$ from the ground level and the installed sensor's measurement result. Validation results of SED values are $2.5 \pm 0.3,2.2 \pm 0.6,2.0 \pm 1.1$, in R15, R33, and R40, respectively. In general, these results can be said to meet the design demands with an average SED of less than 2.5. However, large variations occur in the test results in naturally ventilated classrooms, R33 and R40. If we look at the SED graph of the test results in Figure 18, this considerable SED variation is caused by the large SED variations in the air velocity dimensions. SED variations in the air velocity dimension arise because, during the test, the classroom's door and windows are opened. There is a difference in the air velocity value detected by the measuring instrument at the test point position with

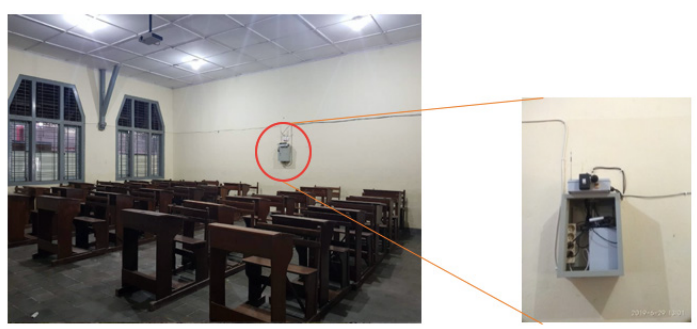

Figure 17: The installed sensor in the selected position in the $R 40$ classroom the installed sensor value. This difference is more visible because the measuring instrument's resolution is 0.1 $\mathrm{m} / \mathrm{s}$. In contrast, according to the simulation results, the difference can occur with a value smaller than the measuring instrument's resolution.

\section{CONCLUSIONS}

Based on the discussion, it can be concluded that,

1. Models of indoor and school area environments succeed in IES-VE software with a residual value of less than $10^{-2}$. Model validation using field measurement resulted in a maximum RMSE value of $0.8^{\circ} \mathrm{C}, 3.5 \%$, and $0.08 \mathrm{~m} / \mathrm{s}$ for indoor temperature, relative humidity, and air velocity variables.

2. The indoor environment position in the school area significantly influences the indoor thermal environment. With the same materials, north-south orientation and no shading from surrounding building cause the roof and wall irradiation flux of R15 classroom is higher than R33 and R40, with an average of $238 \mathrm{~W} / \mathrm{m}^{2}$ and $213 \mathrm{~W} / \mathrm{m}^{2}$ respectively for the ceiling and walls. The heat stored in the building attached to the R33 classroom makes the indoor air temperature not fluctuating throughout the year, and reaching $28.9 \pm 0.1^{\circ} \mathrm{C}$. Wind with a velocity of $0.4 \mathrm{~m} / \mathrm{s}$ enters from both sides of openings in R40 classroom, which have a non-solid structure, causing air velocity variation inside the room with a value of $0.12 \pm 0.14 \mathrm{~m} / \mathrm{s}$ and an even air temperature distribution.

3. Sensor positions with the best performance in representing the indoor thermal environment at the height of $1.1 \mathrm{~m}$ are $\mathrm{B} 5$ for R15, D4 for R33, and B6 for R40. These positions are selected by considering the occupant's activity, safety, installation convenience, and SED analysis, showing accuracy, consistency, and $\%$ coverage of a sensor position. Validation
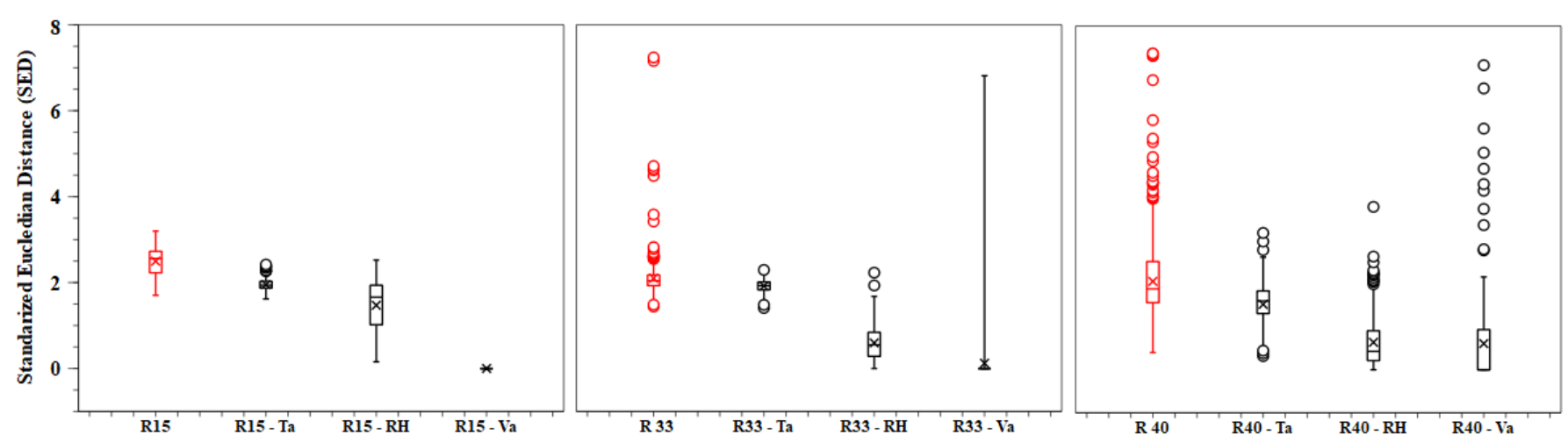

Figure 18: Distribution of SED value from sensor measurement results in the selected positions and SED for each dimension component, including temperature $\left(t_{a}\right)$, relative humidity $(R H)$, and air velocity $\left(v_{a}\right)$ 
results show that sensors in the selected positions could detect thermal variables at the height of 1.1 $\mathrm{m}$ with SED validation values of $2.5 \pm 0.3,2.2 \pm 0.6$, 2.0 1 1.1, for R15, R33, and R40.

This paper focuses on the method in selecting the optimal sensor positions to obtain the most accurate data to represent the thermal environment characteristics of the occupant activity area. The sensors' accuracy influences the overall performance of the BMS in its function as a system to monitor indoor thermal comfort in an energy efficient building. Data accuracy also depends on the sensor's specification, which includes the data resolution during the sensor readings. Hence, the resolution should match with the indoor thermal environment characteristics produced from the CFD simulations. However, this issue is still considered as the limitation of this research and must be included in future work.

\section{ACKNOWLEDGEMENT}

This research is supported by the Indonesian Ministry of Higher Education and Technology through a funding scheme PTUPT No. 2925/UN1.DITLIT/D IT-LIT/PT/2020 and Universitas Gadjah Mada Indonesia. The author would also like to thank Integrated Smart and Green Building (Insgreeb) Research Group and PT. Amakusa for their support throughout the developing process and testing of the system in this research.

\section{DATA AVAILABILITY}

The indoor thermal environment data used to support this study's findings have not been made available due to the agreement with the research partner remaining in process.

\section{CONFLICTS OF INTEREST}

The author(s) declare(s) that there is no conflict of interest regarding the publication of this paper.

\section{REFERENCES}

1. H. Batih and C. Sorapipatana. (2016). Characteristics of urban households' electrical energy consumption in Indonesia and its saving potentials. Renew. Sustain. Energy Rev., vol. 57, pp. 1160-1173, DOI: 0.1016/j. rser.2015.12.132.

2. ASHRAE Standard 55. (2010). Thermal environmental conditions for human occupancy. American Society of Heating Refrigerating and Air-Conditioning Engineers, Inc, Atlanta.

3. P. Fanger. (1970). Thermal comfort: Analysis and Applications in Environmental Engineering. Danish Technical Press, Copenhagen, Denmark.

4. K. Parsons. (2003). Human Thermal Environments: The Effects of Hot, Moderate, and Cold Environments on Human Health, Comfort and Performance, Second Edition. Taylor \& Francis Group, Boca Raton.
5. M. J. Varas-Muriel, R. Fort, M. I. Martínez-Garrido, A. Zornoza-Indart, and P. López-Arce. (2014). Fluctuations in the indoor environment in Spanish rural churches and their effects on heritage conservation: Hygro-thermal and $\mathrm{CO} 2$ conditions monitoring. Build. Environ., vol. 82, pp. 97-109, DOI: 10.1016/j.buildenv.2014.08.010.

6. W. Rattanongphisat, T. Prachaona, A. Harfield, K. Sato, and O. Hanaoka. (2017). Indoor Climate Data Analysis Based a Monitoring Platform for Thermal Comfort Evaluation and Energy Conservation. Energy Procedia, vol. 138, pp. 211-216, DOI: 10.1016/j.egypro.2017.10.152.

7. M. W. Ahmad, M. Mourshed, D. Mundow, M. Sisinni, and Y. Rezgui. (2016). Building energy metering and environmental monitoring - A state-of-the-art review and directions for future research. Energy Build., vol. 120, pp. 85-102, DOI: 0.1016/j.enbuild.2016.03.059.

8. T. Seabrook. (2016). Optimal Placement Strategies of Minimum Effective Sensors for Application in Smart Buildings. Energy and Buildings, vol 158, pp. 12061225, DOI: 10.1016/j.enbuild.2017.10.074.

9. H. Hayat et al. (2019). The state-of-the-art of sensors and environmental monitoring technologies in buildings. Sensors (Switzerland), vol. 19, no. 17, DOI: 10.3390/s19173648.

10. D. G. Eliades, M. P. Michaelides, C. G. Panayiotou, and M. M. Polycarpou. (2013). Security-oriented sensor placement in intelligent buildings. Build. Environ., vol. 63, pp. 114-121, DOI: 10.1016/j.buildenv.2013.02.006

11. H. Sharma, U. Vaidya, and B. Ganapathysubramanian. (2019). A transfer operator methodology for optimal sensor placement accounting for uncertainty. Build. Environ., vol. 155, no. March, pp. 334-349, DOI: 10.1016/j.buildenv.2019.03.054.

12. J. Waeytens and S. Sadr. (2018). Computer-aided placement of air quality sensors using adjoint framework and sensor features to localize indoor source emission. Build. Environ., vol. 144, no. August, pp. 184-193, DOI: 10.1016/j.buildenv.2018.08.012.

13. R. J. Yanti, Faridah, I. W. Mustika, D. D. Ariananda, and S. S. Utami. (2020). Analysis of Gaussian process to predict thermal sensor placement for controlling energy consumption on the educational building. AIP Conference Proceedings, vol. 2223, DOI: 10.1063/5.0000923.

14. S. Yeon Lee, I. bok Lee, U. Hyeon Yeo, R. woo Kim, and J. Gyu Kim. (2019). Optimal sensor placement for monitoring and controlling greenhouse internal environments. Biosyst. Eng., vol. 188, pp. 190-206, DOI: 10.1016/j.biosystemseng.2019.10.005. 
15. D. Yoganathan, S. Kondepudi, B. Kalluri, and S. Manthapuri. (2018). Optimal sensor placement strategy for office buildings using clustering algorithms. Energy Build., vol. 158, pp. 1206-1225.

16. P. Erickson, M. Cline, N. Tirpankar, and T. Henderson. (2015). Gaussian processes for multi-sensor environmental monitoring. IEEE Int. Conf. Multisens. Fusion Integr. Intell. Syst., vol. 2015-October, pp. 208-213, DOI: 10.1109/MFI.2015.7295810.

17. M. Al-Kuwari, A. Ramadan, Y. Ismael, L. Al-Sughair, A. Gastli, and M. Benammar. (2018). Smart-home automation using loT-based sensing and monitoring platform. Proc. - 2018 IEEE 12th Int. Conf. Compat. Power Electron. Power Eng. CPE-POWERENG 2018, pp. 1-6, DOI: 10.1109/CPE.2018.8372548.

18. P. Zhou, G. Huang, L. Zhang, and K. F. Tsang. (2015). Wireless sensor network based monitoring system for a large-scale indoor space: Data process and supply air allocation optimization. Energy Build., vol. 103, pp. 365-374, DOI: 10.1016/j.enbuild.2015.06.042.

19. Y. Jin, Y. Xiong, L. Wang, Y. X. Liu, and Y. Zhang. (2018). Eco-feedback for thermal comfort and cost efficiency in a nearly zero-energy residence in Guilin, China. Energy Build., vol. 173, pp. 1-10, DOI: 10.1016/j.enbuild.2018.04.025.

20. M. Greenacre and R. Primicerio. (2013). Multivariate Analysis of Ecological Data, Rubes Edit. Spain: Fundación BBVA.
21. R. Geiger, H. Aron, and P. Todhunter. (1961). The Climate Near the Ground, 5th ed. Harvard University Press, Cambridge, Mass.

22. A. Al-janabi, M. Kavgic, A. Mohammadzadeh, and A. Azzouz. (2019). Comparison of EnergyPlus and IES to model a complex university building using three scenarios: Free-floating, ideal air load system, and detailed. J. Build. Eng., vol. 22, no. September 2018, pp. 262-280, DOI: 10.1016/j.jobe.2018.12.022.

23. D. B. Crawley, J. W. Hand, M. Kummert, and B. T. Griffith. (2008). Contrasting the capabilities of building energy performance simulation programs. Build. Environ., vol. 43, no. 4, pp. 661-673, DOI: 0.1016/j. buildenv.2006.10.027

24. Jamal M Saleh. (2002). Fluid flow handbook. McGraw-Hill, New York.

25. Hugo Hens. (2017). Building Physics Heat, Air, and Moisture: Fundamentals and Engineering Methods with Examples and Exercices, Third.Wilhelm Ernst \& Sohn, Germany.

26. T. R. Oke, G. Mills, A. Christen, and J. A. Voogt. (2017). Urban Climates. Cambridge University Press, UK.

27. I. Kurniawan, Faridah, and S. S. Utami. (2020). Characterizing of climate chamber thermal environment using the CFD simulation method using IES VE. AIP Conference Proceedings, vol. 2223, DOI: 10.1063/5.0000924. 